University of Nebraska - Lincoln

DigitalCommons@University of Nebraska - Lincoln

West Central Research and Extension Center, North Platte

Agricultural Research Division of IANR

2019

\title{
Approaches to evaluating grower irrigation and fertilizer nitrogen amount and timing
}

Tsz Him Lo

Daran Rudnick

Charles Burr

Matt Stockton

Rodrigo Werle

Follow this and additional works at: https://digitalcommons.unl.edu/westcentresext

Part of the Agriculture Commons, Ecology and Evolutionary Biology Commons, and the Plant Sciences Commons

This Article is brought to you for free and open access by the Agricultural Research Division of IANR at DigitalCommons@University of Nebraska - Lincoln. It has been accepted for inclusion in West Central Research and Extension Center, North Platte by an authorized administrator of DigitalCommons@University of Nebraska Lincoln. 


\title{
Approaches to evaluating grower irrigation and fertilizer nitrogen amount and timing
}

\author{
Tsz Him Lo, ${ }^{1}$ Daran R. Rudnick, ${ }^{1}$ Charles A. Burr, ${ }^{1}$ \\ Matthew C. Stockton, ${ }^{1} \&$ Rodrigo Werle ${ }^{2}$
}

1 West Central Research and Extension Center, University of Nebraska-Lincoln, North Platte, NE, 69101, United States

2 Department of Agronomy, University of Wisconsin-Madison, Madison, WI, 53706, United States

Corresponding author — D. R. Rudnick, email daran.rudnick@unl.edu

\begin{abstract}
Diversity in the knowledge, mindset, strategies, and tools that growers use to manage irrigation and fertilizer nitrogen culminates in diversity in profitability and environmental impact among farms. As growers, academia, and industry strive together to tackle the technological and non-technological challenges impeding better irrigation and fertilizer nitrogen management, a science-based evaluation of grower input amount and timing becomes an important initial step in the process. Providing such valuable feedback to growers is a high-priority objective for the University of NebraskaLincoln Testing Ag Performance Solutions (UNL-TAPS) farm management competition. In this competition, each team of mostly growers made management decisions for field corn in three replicated plots within the same field at the West Central Research and Extension Center in North Platte, NE, and vied for maximum profitability and most judicious input management. The 2017 dataset affirmed existing theory predicting that many efficiency indices strictly decrease in value with increasing seasonal input amount and thus would fail to point towards an appropriate input level. Furthermore,
\end{abstract}

Published in Agricultural Water Management 213 (2019) 693-706

doi:10.1016/j.agwat.2018.11.010

Copyright (C) 2018 Elsevier B.V. Used by permission.

Submitted 4 October 2018; accepted 12 November 2018; published 23 November 2018. 
grain yield was heavily affected by cultivar choice, so efficiency indices that depend on yield actually obscured rather than facilitated the evaluation of irrigation and fertilizer nitrogen management. An alternate evaluation approach is to compare a grower's seasonal input amount or input temporal distribution against an appropriate range enveloped by university recommendations on the high end and observed yield-limiting thresholds on the low end. Where irrigation and fertilizer nitrogen are relatively inexpensive and where producing near-maximum yield is optimal, this approach is suitable for analyzing an input in isolation and for analyzing multiple inputs simultaneously.

Keywords: Efficiency, Evaluation, Irrigation, Nitrogen, Requirement, UNL-TAPS

\section{Introduction}

Increasing crop production while limiting adverse environmental impacts is a widely stated goal in agricultural science, and more judicious application of inputs is regarded as one primary means of achieving this goal. Excessive input application relative to crop requirements not only can decrease farm profits but also can degrade the environment. Excessive irrigation can unsustainably deplete groundwater and streamflow, whereas excessive fertilizer nitrogen can waste fossil fuels, generate additional greenhouse gases, and contaminate surface water and groundwater. Thus, much research has occurred to develop scientific methods to better match the amount and timing of input availability to the amount and timing of crop demand. Examples of such methods include crop coefficients $\left(\mathrm{K}_{\mathrm{c}}\right)$, soil moisture sensors, and infrared thermometry for irrigation (Taghvaeian et al., 2012; Bartlett et al., 2015; Rudnick et al., 2015; Singh et al., 2018) and include soil testing, tissue sampling, controlled release formulations, and active optical sensors for fertilizer nitrogen (Ferguson, 2015; Thompson et al., 2015).

Although the science and engineering of many methods can be further refined, arguably the greatest barriers to further improving on-farm input management are not technological. Adopting one of these methods effectively on a farm can be extremely challenging due to g reasons alone. Growers would need to become convinced about the need to improve input management, become informed about the tools available, become comfortable with using a subset of one or more tools, and become successful in integrating that subset of tools into their operations. This process often necessitates substantial time, knowledge, money, and mindset changes. 
While extension will not enable growers to bypass this process, one of the ways extension can ease this process is by providing quantitative evaluation of input management to inform growers' learning by doing. Growers usually notice their crop yield and farm profitability but may be less aware of the quality of their input management. Input management evaluation would identify how each grower can improve the amount and/or timing of irrigation and fertilizer nitrogen. This objective information would then become a starting point for in-depth discussion among growers, industry, and university staff on how mentalities, technologies, and strategies can be revised for future years.

However, the evaluation of grower decisions may need to differ from that of highly controlled experiments. First, ideal evaluation methods must consider both irrigation and nitrogen management because the two inputs are tightly linked and contribute jointly to crop performance. Second, ideal evaluation methods must be flexible enough to handle the countless ways growers may vary the amount and timing of irrigation and fertilizer nitrogen. Third, ideal evaluation methods must be resistant to cultivar effects.

This paper examines methods for evaluating the amount and timing of irrigation and fertilizer nitrogen through an on-station farm management competition dataset. Efficiency indices-numerical ratios of crop output over crop input-may be the first method that comes to mind, but not all conventional efficiency indices prove to be suitable for this purpose. Two new sets of efficiency indices and a requirement range approach are therefore proposed in response to the shortcomings of conventional efficiency indices. Finally, the paper further discusses the general applicability of these methods to various contexts.

\section{Methods}

\subsection{Background}

The University of Nebraska-Lincoln Testing Ag Performance Solutions (TAPS; taps.unl.edu) program hosted a farm management competition in 2017, where growers competed for maximum profitability and optimal input (irrigation and fertilizer nitrogen) management. There were a total of fifteen teams, where each team (grower or group of growers) 
made irrigation, fertilizer, planting, marketing, and insurance decisions for a 1214 ha farm simulated by plots at the UNL West Central Research and Extension Center in North Platte, NE. In a zero-risk setting, the teams were able to try technologies and strategies hands-on and had various opportunities to learn with/from peers, industry, and university staff regarding technological and non-technological challenges of input management. The centralized location facilitated the collection of diverse measurements, the comparison between contestant farms, and the hosting of in-depth field day workshops.

Each contestant team was randomly assigned three replicate 0.05 ha plots inside a no-till irrigated field following soybean. Preplant fertilizer was applied on 4 May by a double-coulter liquid applicator dribbling urea ammonium nitrate (UAN) 32-0-0 at a depth of 0.02m and at a distance of $0.13 \mathrm{~m}$ from the center of the crop row on both sides. Hybrid field corn (Zea mays) was planted $0.05 \mathrm{~m}$ deep on 9 May with $0.76 \mathrm{~m}$ row spacing at rates of 69,200 to 85,300 seeds ha ${ }^{-1}$ as decided by each contestant team. Sidedress fertilizer was applied on 12 June (V5 growth stage) by the same liquid applicator dribbling UAN 32-0-0 at a depth of $0.02 \mathrm{~m}$ and at a distance of $0.19 \mathrm{~m}$ from the center of the crop row on both sides. All teams had two opportunities per week to irrigate up to $25 \mathrm{~mm}$. Irrigation was applied using a variable rate center pivot with solenoid valves to pulse pairs of sprinklers independently. The sprinkler package was low-pressure stationary spray heads at $0.6 \mathrm{~m}$ height in alternate interrows (i.e., 1.5m sprinkler spacing). Additionally, all teams had four opportunities during the growing season to fertigate up to 34 $\mathrm{kg} \mathrm{ha}^{-1}$ of nitrogen (all fertilizer nitrogen rates in this paper refers to the mass of nitrogen and not the mass of fertilizer product). The application dates were 29 June, 13 July, 20 July, and 2 August (V9, V14, R1, and R2 growth stages). Fertigation was applied through the center pivot using a variable rate injection pump that maintains the system concentration of UAN 32-0-0 even as the irrigation system flow rate changed. Silking and physiological maturity were generally reached on 20 July and 10 October, respectively. A killing frost also occurred on the morning of 10 October, which ended the growing season for all farms.

The 2017 growing season in North Platte was characterized by relatively long alternating periods of high and low evaporative demand (Fig. 1). Minimal rainfall occurred during the periods of high evaporative demand, while the transitions from high to low evaporative demand 


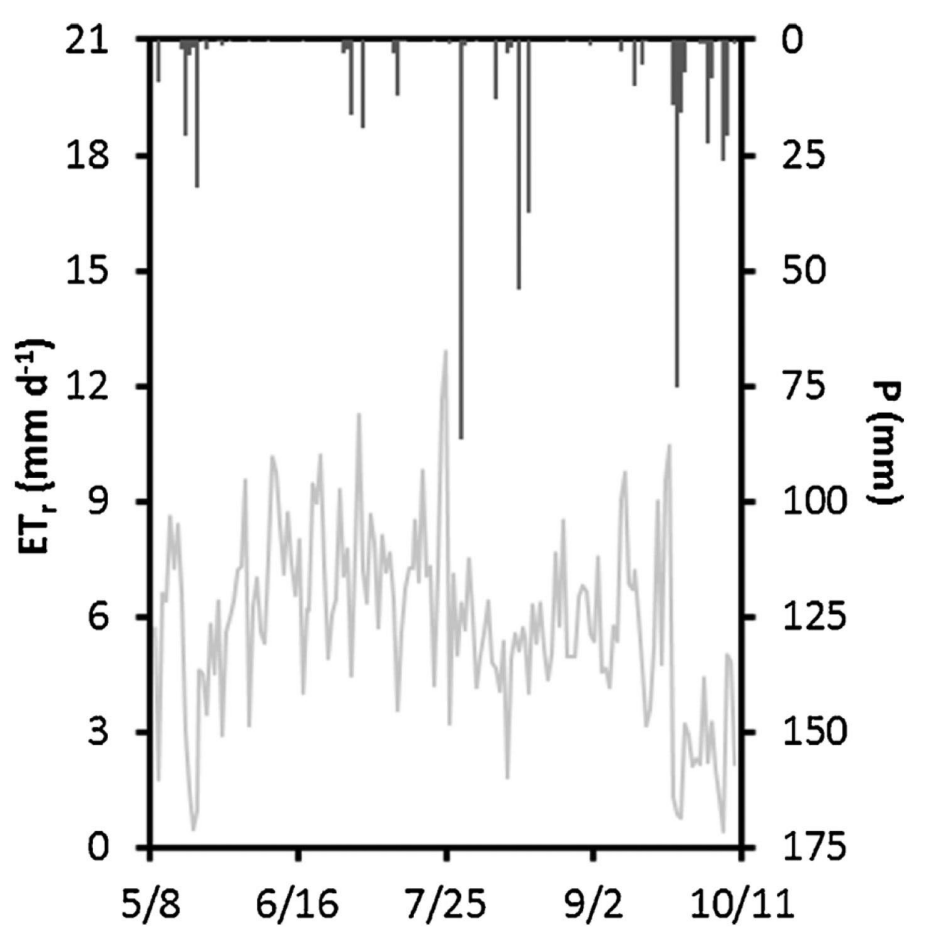

Fig. 1. Alfalfa reference evapotranspiration (ETr; Allen et al., 2005) and rainfall (P) during the competition; precipitation records were the average of four manual rain gauges along the field edge, whereas all other weather records were provided by the Nebraska State Climate Office from its North Platte $3 \mathrm{SW}$ station $1.6 \mathrm{~km}$ away.

were abrupt and began with heavy rainfall. The periods of high evaporative demand were the first half of May, early June to late July, and late August to late September. The periods of low evaporative demand were the second half of May, late July to late August, and late September to early October.

\subsection{Data collection}

Locally calibrated 503 Elite Hydroprobe neutron moisture meters (Campbell Pacific Nuclear, Concord, CA) were used to determine the crop evapotranspiration (ET) in each plot during the growing season. On 12 measurement dates, a $15 \mathrm{~s}$ neutron count was measured at depths of $0.15,0.46,0.76,1.07,1.37$, and $1.68 \mathrm{~m}$ in one tube per plot. Crop ET between two measurement dates can be directly calculated from the change in total water over the $1.83 \mathrm{~m}$ profile whenever runoff 
and deep percolation are negligible. This assumption was deemed appropriate for the intervals between seven pairs of measurement dates. None of these intervals were preceded by or contained heavy rainfall, and total runoff during each interval was estimated to be less than $1 \mathrm{~mm}$ when conservatively assuming a runoff curve number of 80 that corresponds to poor hydrologic condition (NRCS, 2004). During each interval, crop ET equaled precipitation plus irrigation minus change in total water over the $1.83 \mathrm{~m}$ profile. For each plot, a piecewise linear curve (in the style of Allen et al., 1996) of alfalfa reference stressed mean crop coefficients $\left(\mathrm{K}_{\mathrm{s}} \times \mathrm{K}_{\mathrm{cr}}\right)$ as a function of growing degree days was fitted by minimizing the sum of squared differences between observed and modeled crop ET during those seven intervals, with each difference weighted by the number of days during the interval. This approach was chosen because the errors of $\mathrm{K}_{\mathrm{s}} \times \mathrm{K}_{\mathrm{cr}}$ curve fitting were expected to be smaller than the uncertainties in daily water balance parameters for runoff, deep percolation, and water stress. Seasonal crop ET for each plot was calculated by summing the daily product between $\mathrm{K}_{\mathrm{cr}}$ and $\mathrm{ET}_{\mathrm{r}}$. To minimize the effect of outliers, seasonal crop ET for each farm was taken to be the median (rather than average) seasonal ET among the three constituent plots.

On several dates during the growing season, non-contact sensors were mounted at $2.9 \mathrm{~m}$ height to a custom-built tractor-mounted boom for collecting canopy measurements in the core of every plot. The tractor was driven at $1 \mathrm{~m} \mathrm{~s}^{-1}$ in both directions along the alleys between strips of plots so that both the left and right sides of the boom passed once over each plot and so that all measurements were collected generally within one hour during the early or mid afternoon. The left and right sides of the boom were equipped with the identical set of sensors. Each set included two SI-1H1 infrared thermometers (Apogee Instruments, Logan, UT) and one ACS-430 active optical sensor (Holland Scientific, Lincoln, NE). The infrared thermometers were oriented at $60^{\circ}$ from nadir, pointed perpendicular with crop rows away from the tractor, and sampled once every $3 \mathrm{~s}$. The active optical sensor was positioned between crop rows (Shaver et al., 2017), oriented nadir with the longer dimension of the field of view perpendicular with crop rows, and sampled once every $0.1 \mathrm{~s}$. Omitting data from the buffer areas where irrigation and fertilizer nitrogen rates transitioned from those of one plot to those of another plot, each set of sensors collected at least 8 canopy temperature 
measurements and at least 240 canopy reflectance measurements from each plot on each measurement date. Again to minimize the effect of outliers, the canopy temperature and normalized difference red edge (NDRE) vegetation index values for each plot were taken to be the average of the median value according to the left set of sensors and the median value according to the right set of sensors.

Destructive sampling was also performed in each plot. The uppermost collared leaf from each of 12 plants per plot was sampled on 13 July 2017 (approximately V14 according to the leaf collar system of vegetative growth stages) immediately before the second fertigation application. On 16 October (after physiological maturity), the corn ears and the $0.20 \mathrm{~m}$ segment of stalk from 0.15 to $0.36 \mathrm{~m}$ above the ground were sampled from each of ten plants per plot. The grain from those ten plants was separated from the cobs using an electrically powered mechanical sheller. Leaf nitrogen content, stalk nitrate content, and grain nitrogen content analyses were conducted by Ward Laboratories (Kearney, NE). On 2 November, the grain from the middle $18 \mathrm{~m}$ of the center six crop rows in each plot was harvested using a six-row combine. Grain moisture content was measured using the moisture sensor of the yield monitor system inside the combine, and wet grain weight was measured using a weigh wagon. Market grain yield $(\mathrm{Y})$ was normalized to $15.5 \%$ grain moisture, and grain nitrogen uptake (G) was calculated as the product of dry grain yield and grain nitrogen content. Again to minimize the effect of outliers, $Y$ and $G$ for each farm were taken to be the median $Y$ and $\mathrm{G}$ among the three constituent plots.

\subsection{Efficiency indices}

An efficiency index, by definition, is a ratio of output over input and thus can be represented by a slope (i.e., ratio of rise over run) on a graph that plots an output variable on the vertical axis and an input variable on the horizontal axis. Eight conventional efficiency indices for irrigation and nitrogen management are depicted in Figs. 2a-f, and the corresponding equations (equations 1-8) are listed below. Indices 2-4 were calculated according to Rudnick and Irmak (2013). Indices 5-8 were calculated according to Dobermann (2007), but G was substituted for aboveground nitrogen uptake $(\mathrm{U})$ because the latter was not measured in the 2017 UNL-TAPS competition. If $\mathrm{U}$ was used instead, Figs. $2 \mathrm{~d}$-e and 

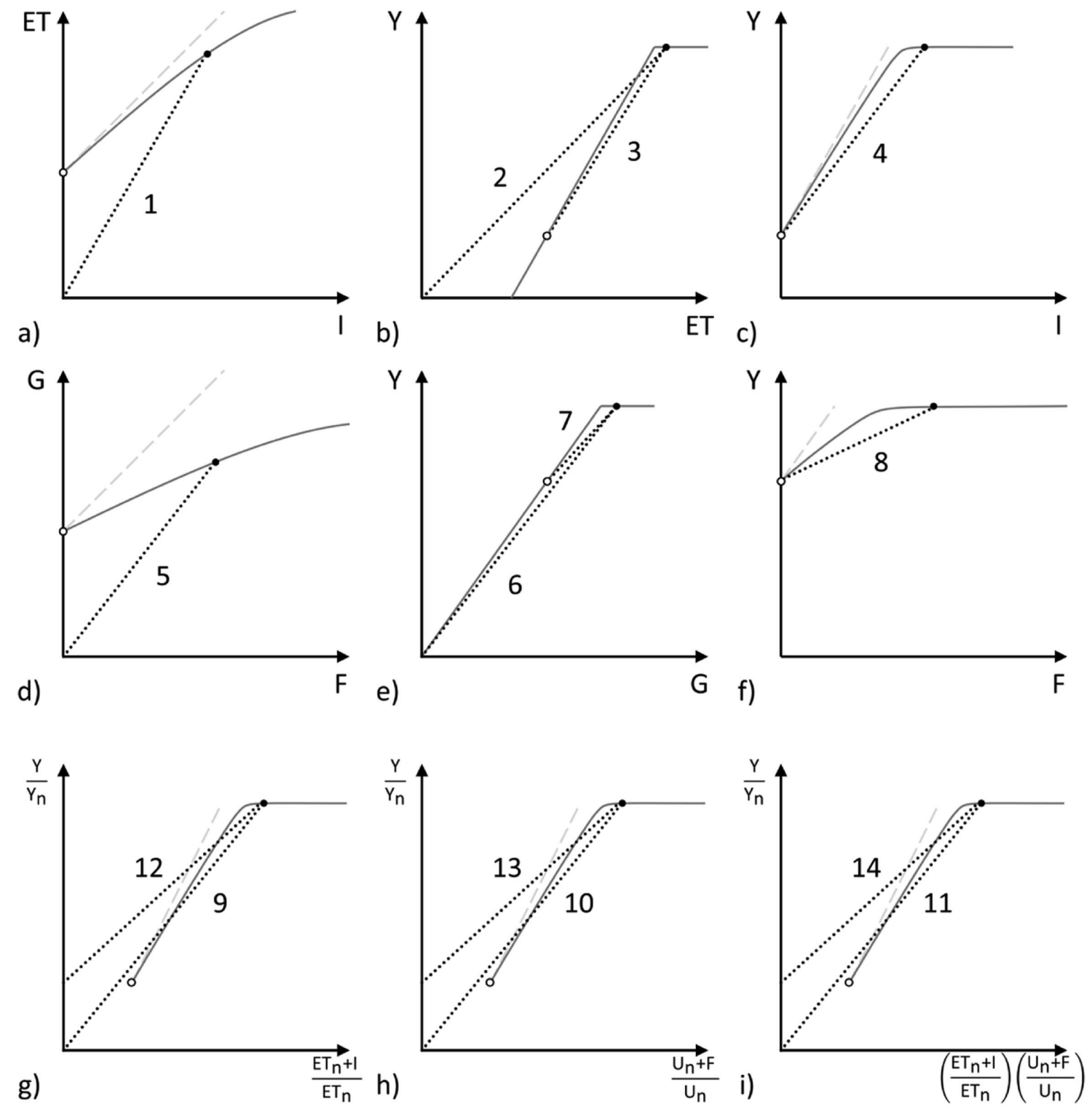

Fig. 2. Theoretical relationships between irrigation (I), crop evapotranspiration (ET), and grain yield $(\mathrm{Y})$ and between fertilizer nitrogen $(\mathrm{F})$, grain nitrogen uptake $(\mathrm{G})$, aboveground nitrogen uptake (U), and Y; the black dotted lines (labelled 1-14) represent different efficiency indices describing the farm under evaluation (solid circles) sometimes relative to a zero-input treatment (hollow circles); and the long grey dashed lines denote perfect conversion of I to ET or F to G. 
the associated indices would be more similar to Figs. $2 \mathrm{a}-\mathrm{b}$ and the associated indices, respectively. Indices $1,3,4,5,7$, and 8 were not calculated for the zero-input treatment (i.e., nonirrigated and unfertilized; farm 7) because the index value would be undefined. The line with long grey dashes denotes perfect conversion of irrigation (I) to evapotranspiration (ET) in Figs. 2a and 2c, whereas it denotes perfect conversion of fertilizer nitrogen (F) to G in Figs. 2 d and 2f. Fig. 2 shows only the rising and plateau segments of the theoretical water and nitrogen production functions. The declining segment of the production functions can be relevant for some combinations of crop, cultivar, environment, and management but is rarely observed under the conditions and input levels observed in the 2017 UNL-TAPS competition. While this paper focuses on the rising and plateau segments of production functions, the analyses and conclusions remain valid on a declining segment.

\section{Irrigation Efficiency (IE):}

$$
I E=\frac{E T-E T_{n}}{I}
$$

where

ET = crop evapotranspiration of the farm under evaluation [L]

$\mathrm{ET}_{\mathrm{n}}=$ crop evapotranspiration of the zero-input treatment [L]

$\mathrm{I}=$ gross irrigation applied by the farm under evaluation [L]

\section{Crop Water Use Efficiency (CWUE):}

$$
C W U E=\frac{Y}{E T}
$$

where

$\mathrm{Y}=$ grain yield of the farm under evaluation $\left[\mathrm{M} / \mathrm{L}^{2}\right]$

\section{Evapotranspiration Water Use Efficiency (ETWUE):}

where

$$
E T W U E=\frac{Y-Y_{n}}{E T-E T}
$$

$\mathrm{Y}_{\mathrm{n}}=$ grain yield of the zero-input treatment $\left[\mathrm{M} / \mathrm{L}^{2}\right]$

\section{Irrigation Water Use Efficiency (IWUE):}

$$
I W U E=\frac{Y-Y_{n}}{I}
$$




\section{Recovery Efficiency (RE):}

$$
R E=\frac{G-G_{n}}{F}
$$

where

$\mathrm{G}=$ grain nitrogen uptake of the farm under evaluation $\left[\mathrm{M} / \mathrm{L}_{2}\right]$

$\mathrm{G}_{\mathrm{n}}=$ grain nitrogen uptake of the zero-input treatment $\left[\mathrm{M} / \mathrm{L}_{2}\right]$

$\mathrm{F}=$ fertilizer nitrogen applied by the farm under evaluation $\left[\mathrm{M} / \mathrm{L}_{2}\right]$

Internal Efficiency (NE):

$$
N E=\frac{Y}{G}
$$

\section{Physiological Efficiency (PE):}

$$
P E=\frac{Y-Y_{n}}{G-G_{n}}
$$

\section{Agronomic Efficiency (AE):}

$$
A E=\frac{Y-Y_{n}}{F}
$$

Suppose that total water input and total nitrogen input are considered to be the sum of a naturally supplied component and a management supplied component. Specifically, total water input equaled ET of the zeroinput treatment $\left(\mathrm{ET}_{\mathrm{n}}\right)$ plus I of the farm under evaluation, while total nitrogen input equaled $U$ of the zero-input treatment $\left(U_{n}\right)$ plus $F$ of the farm under evaluation. Y, total water input and total nitrogen input can then be divided by $\mathrm{Y}$ of the zero-input treatment $\left(\mathrm{Y}_{\mathrm{n}}\right), \mathrm{ET}_{\mathrm{n}}$ and $\mathrm{U}_{\mathrm{n}}$, respectively, for non-dimensionalization. One new set of efficiency indices can be calculated as the ratio of dimensionless yield over dimensionless total input. These new indices-without non-dimensionalization - would be almost the same as CWUE and NE when considering just one input (i.e., water or nitrogen), but non-dimensionalization is necessary when considering water and nitrogen simultaneously. The value of these new indices always equals 1 for the zero-input treatment. Farms that produce more Y per unit of total input (i.e., more "efficient") than the zero-input treatment achieve index values exceeding 1 . Those that produce less Y per unit of total input (i.e., less "efficient") than the zero-input treatment achieve index values below 1 . Another new set of efficiency indices can be calculated as the ratio of dimensionless yield increase (i.e., 
$\left.\left(Y-Y_{n}\right) / Y_{n}\right)$ over dimensionless total input. The value of these new indices always equals 0 for the zero-input treatment. All farms that produce more $Y$ than the zero-input treatment achieve positive index values, but the yield increase is discounted by the magnitude of dimensionless total input. The first new set of three efficiency indices (equations 9-11) and the second new set of three efficiency indices (equations 12-14) are depicted in Figs. 2g-i, and the corresponding equations are listed below. Again, the line with long grey dashes denotes perfect conversion of I to ET in Fig. 2g, of F to U in Fig. $2 \mathrm{~h}$, and of both I and F to ET and U in Fig. 2i. For purpose of illustration, $U_{n}$ was assumed to be $210 \mathrm{~kg} \mathrm{ha}^{-1}$ by adding an estimate of aboveground stover nitrogen uptake (Wortmann et al., 2012) to the measured $G$ of the zero-input treatment.

\section{Relative Water Input Efficiency (RWIE):}

$$
R W I E=\frac{Y / Y_{n}}{\left(E T_{n}+I\right) / E T_{n}}
$$

Relative Nitrogen Input Efficiency (RNIE):

$$
R N I E=\frac{Y / Y_{n}}{\left(U_{n}+F\right) / U_{n}}
$$

Relative Water $\times$ Nitrogen Input Efficiency (RWNIE):

$$
R W N I E=\frac{\left(Y / Y_{n}\right)}{\left(\frac{E T_{n}+I}{E T_{n}}\right)\left(\frac{U_{n}+F}{U_{n}}\right)}
$$

Water Intensification Performance Index (WIPI):

$$
W I P I=\frac{\left(Y-Y_{n}\right) / Y_{n}}{\left(E T_{n}+I\right) / E T_{n}}
$$

Nitrogen Intensification Performance Index (NIPI):

$$
N I P I=\frac{\left(Y-Y_{n}\right) / Y_{n}}{\left(U_{n}+F\right) / U_{n}}
$$

Water $\times$ Nitrogen Intensification Performance Index (WNIPI):

$$
W N I P I=\frac{\left(Y-Y_{n}\right) / Y_{n}}{\left(\frac{E T_{n}+I}{E T_{n}}\right)\left(\frac{U_{n}+F}{U_{n}}\right)}
$$




\subsection{Input requirement ranges}

This paper assumes the supply of I and F is plentiful enough that producing (near) maximum $Y$ is optimal. This assumption is still the reality for the competition site at the time of writing but certainly is not the reality everywhere every year. If the physical, economic, and/or legal/ regulatory scarcity of I and $\mathrm{F}$ is so severe that the optimal production is significantly lower than maximum yield, the evaluation of input management becomes a much more sophisticated optimization problem that is far beyond the scope of this paper.

University extension recommendations are typically intended to maximize yield or profit amid uncertainties in weather, equipment, and information (Shapiro et al., 2008). Therefore, the input quantity that is applied when following university extension recommendations tends to be larger than the minimum input quantity that is required for producing maximum yield. In this paper, the higher I and $\mathrm{F}$ requirements according to university extension recommendations are denoted as $\mathrm{I}_{\text {req, } \mathrm{H}}$ and $\mathrm{F}_{\text {req, } \mathrm{H}}$, respectively. On the other hand, the lower I and F requirements to prevent narrowly any yield loss due to input deficiencies are denoted as $\mathrm{I}_{\text {req,L }}$ and $\mathrm{F}_{\text {req, }}$, respectively. For both $\mathrm{I}$ and $\mathrm{F}$, the seasonal and daily seasonto-date input quantities of the farm under evaluation can be compared with the seasonal and daily season-to-date higher and lower requirements upon the conclusion of the growing season. An input quantity may be deemed appropriate if it falls between the higher and lower requirements and deemed inappropriate otherwise.

Alternatively, metrics can be constructed to quantify the seasonal or daily deviation of the farm under evaluation from the center of the range spanned by the higher and lower requirements. The first three metrics below (equations 15-17) summarize seasonal deviation from the center of range, whereas the second three metrics (equations 18-20) summarize daily season-to-date deviation from the center of range.

\section{Relative Deviation in Irrigation $\left(\mathrm{RD}_{\mathrm{I}}\right)$ :}

where

$$
R D_{I}=\frac{I-I_{c o r}}{I_{c o r}}
$$

$I_{\text {cor }}=$ seasonal irrigation for the center of range 


\section{Relative Deviation in Fertilizer Nitrogen $\left(\mathrm{RD}_{\mathrm{F}}\right)$ :}

where

$$
R D_{F}=\frac{F-F_{c o r}}{F_{c o r}}
$$

$\mathrm{F}_{\text {cor }}=$ seasonal fertilizer nitrogen for the center of range

\section{Absolute Relative Deviation in Irrigation $\times$ Fertilizer Nitrogen}

$\left(\mathrm{ARD}_{\mathrm{IXF}}\right)$ :

$$
A R D_{I \times F}=\left(1+\left|R D_{I}\right|\right)\left(1+\left|R D_{F}\right|\right)-1
$$

Relative Root Mean Squared Deviation in Irrigation (RRMSD $)$ :

$$
\operatorname{RRMSD}_{I}=\frac{\sqrt{\sum_{t=1}^{T}\left(I_{t}-I_{c o r, t}\right)^{2} / T}}{I_{c o r}}
$$

where

$\mathrm{t}=$ index for days in growing season

$\mathrm{T}=$ total number of days in growing season

$I_{t}=$ season-to-date irrigation for the farm under evaluation on day $t$

$I_{c o r, t}=$ season-to-date irrigation for the center of range on day $t$

\section{Relative Root Mean Squared Deviation in Fertilizer Nitrogen} $\left(\right.$ RRMSD $\left._{\mathrm{F}}\right)$ :

$$
\operatorname{RRMSD}_{F}=\frac{\sqrt{\sum_{t=1}^{T}\left(F_{t}-F_{c o r, t}\right)^{2} / T}}{F_{c o r}}
$$

where

$F_{t}=$ season-to-date fertilizer nitrogen for the farm under evalua-

tion on day $\mathrm{t}$

$\mathrm{F}_{\text {cor, }}=$ season-to-date fertilizer nitrogen for the center of range on day $\mathrm{t}$

\section{Relative Root Mean Squared Deviation in Irrigation $\times$ Fertilizer} Nitrogen $\left(\right.$ RRMSD $\left._{\mathrm{I} \times \mathrm{F}}\right)$ :

$$
R R M S D_{I \times F}=\left(1+R R M S D_{I}\right)\left(1+R R M S D_{F}\right)-1
$$

For the 2017 UNL-TAPS competition, $\mathrm{I}_{\text {req, } \mathrm{H}}$ was determined by modeling the irrigation necessary to meet fully irrigated crop ET while following university extension recommendations. LI-COR Biosciences (Lincoln, 
$\mathrm{NE}$ ) installed an eddy covariance system on the northern edge of a no-till field $1.4 \mathrm{~km}$ away that was growing fully fertilized corn following soybeans and was fully irrigated by a lateral move system. Subsequently, the company provided the authors with final data from its EddyPro processing software. After filtering out data points that were either deemed as low quality by EddyPro or were corresponding to footprints located outside the field based on wind direction, 2265 half-hourly latent heat flux values between 27 April and 22 September remained. Inspection of days with complete data revealed that half-hourly solar radiation $\left(\mathrm{R}_{\mathrm{s}}\right)$ exhibited a strong linear relationship with half-hourly crop ET. To ensure adequate spread in $\mathrm{R}_{\mathrm{s}}$ to develop linear regression for gap filling crop ET, the 48 half-hour intervals in a day were divided into 3 eight-hour bins based on expected clear-sky $\mathrm{R}_{\mathrm{s}}$. Among all dates when half-hourly $\mathrm{R}_{\mathrm{s}}$ was available, 67 days contained at least one $\mathrm{R}_{\mathrm{s}}$ versus crop ET data point in each of the three bins. Only for each of these 67 days, missing half-hourly crop ET was estimated from half-hourly $\mathrm{R}_{\mathrm{s}}$ using date-specific linear regression (average $\mathrm{R}_{2}$ of 0.89 ), and daily crop ET was calculated as the sum of all 48 half-hourly crop ET values. A piecewise linear curve (in the style of Allen et al., 1996) of alfalfa reference mean crop coefficients $\left(\mathrm{K}_{\mathrm{cr}}\right)$ as a function of growing degree days was fitted by minimizing the sum of squared differences between observed and modeled crop ET on those 67 days (Fig. 3). Growth stage records were used to fine-tune the $\mathrm{K}_{\mathrm{cr}}$ curve to match observations of crop development from the 2017 UNLTAPS competition. The seasonal fully irrigated crop ET was modeled to be $641 \mathrm{~mm}$. Assuming a runoff curve number of 75 that corresponds to good hydrologic condition and assuming $20 \mathrm{~mm}$ of irrigation applied at most once every three days whenever soil water depletion exceeded the threshold adapted from UNL extension recommendations, seasonal $\mathrm{I}_{\text {req,H }}$ was found to be $220 \mathrm{~mm}$. The associated irrigation schedule was used to obtain daily season-to-date $\mathrm{I}_{\text {req, }}$.

$I_{\text {req, }}$ for the 2017 UNL-TAPS competition was determined by modeling the minimum irrigation that was required to produce maximum yield with the hybrid chosen by the most contestant farms. This procedure eliminated the noise that was introduced to the yield versus irrigation data by cultivar differences. However, the procedure was valid only if the farms with the most popular hybrid and with seasonal irrigation in the vicinity of seasonal $\mathrm{I}_{\text {req, }}$ also received $\mathrm{F}$ greater than or equal to seasonal $\mathrm{F}_{\text {req, } \mathrm{L}^{\prime}}$ which was later verified to be true. Sufficient spread in seasonal irrigation among the five farms that planted the most popular 


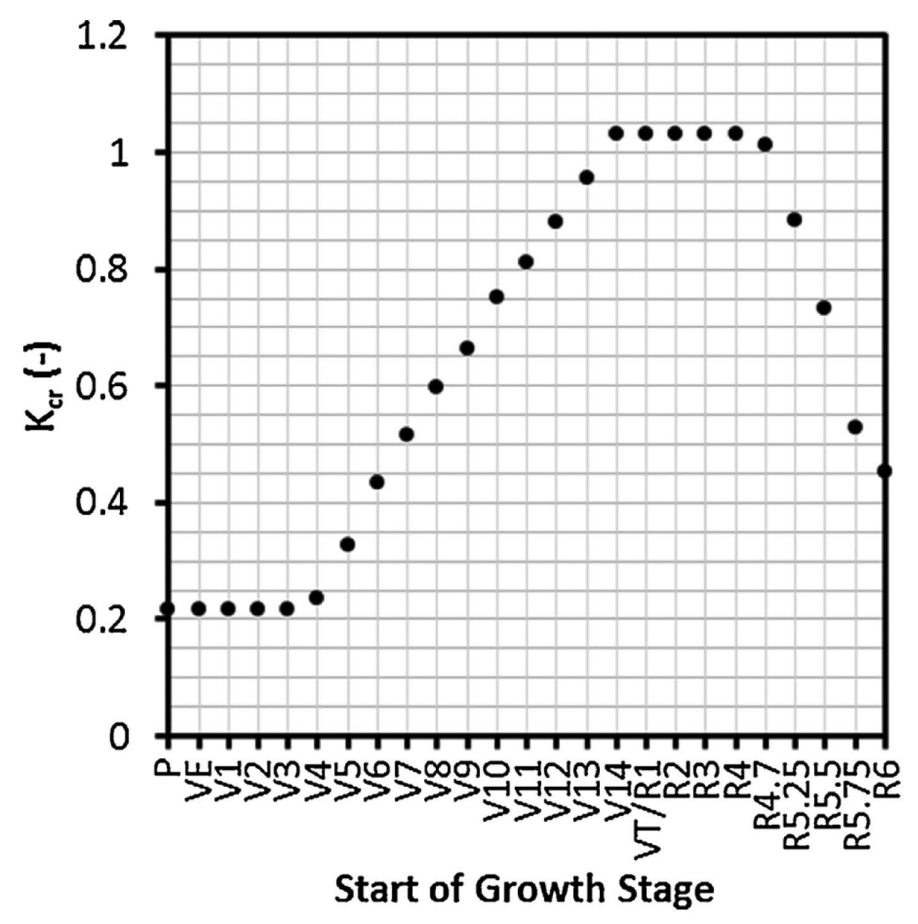

Fig. 3. Alfalfa reference mean crop coefficient $\left(\mathrm{K}_{\mathrm{cr}}\right)$ as a function of growth stage; crop evapotranspiration (ET) during the 2017 growing season was measured using eddy covariance over a no-till field of corn following soybeans fully irrigated by a lateral move system near North Platte, NE.

hybrid Dyna-Gro D53VC55RIB enabled the fitting of a quadratic irrigation water production function. The vertex of the resultant concavedown function corresponded to $150 \mathrm{~mm}$ of seasonal irrigation, which was chosen as seasonal $I_{r e q, L^{-}}$. Daily season-to-date $\mathrm{I}_{\text {req,L }}$ was simplistically assumed to be the same as daily season-to-date $\mathrm{I}_{\mathrm{req}, \mathrm{H}}$ divided by the ratio of seasonal $\mathrm{I}_{\text {req, } \mathrm{L}}$ over seasonal $\mathrm{I}_{\text {req, } \mathrm{H}^{\circ}}$ This assumption is similar to the concept of a limited irrigation treatment whose daily application depths are a fixed percentage of the daily application depths for the fully irrigated treatment (Rudnick et al., 2018).

Seasonal $\mathrm{F}_{\text {req, } \mathrm{H}}$ was determined using the UNL nitrogen algorithm (Shapiro et al., 2008). Soil samples were collected from the competition site on 6 March and were analyzed by Ward Laboratories (Kearney, $\mathrm{NE}$ ). The $0-0.2 \mathrm{~m}$ depth contained $1.9 \%$ organic matter and $8.2 \mathrm{ppm}$ nitrate-nitrogen, whereas the $0.2-0.9 \mathrm{~m}$ depth contained $3.8 \mathrm{ppm}$ nitratenitrogen. With $50 \mathrm{~kg} \mathrm{ha}^{-1}$ nitrogen credit for the previous soybean crop and with a yield goal of $15.1 \mathrm{Mg} \mathrm{ha}^{-1}$, seasonal $\mathrm{F}_{\text {req, }}$ was calculated to be $197 \mathrm{~kg} \mathrm{ha}^{-1}$. 
Seasonal $\mathrm{F}_{\text {req, }}$ was determined by modeling the minimum fertilizer nitrogen that was required to produce maximum yield with one hybrid under full irrigation. The spread in fertilizer nitrogen for any hybrid in the 2017 UNL-TAPS competition was insufficient for curve fitting. Therefore, fertilizer nitrogen production function was taken from an immediately adjacent study where Fontanelle 6A327RBC corn following soybean was subjected to nine nitrogen treatments under full irrigation. The fitted quadratic plateau model indicated that seasonal $\mathrm{F}_{\text {req, }}$ was 78 $\mathrm{kg} \mathrm{ha}^{-1}$ (B. T. Krienke et al., unpublished preliminary data, 2017).

Seasonal irrigation and seasonal fertilizer nitrogen for the center of range $\left(185 \mathrm{~mm}\right.$ and $137 \mathrm{~kg} \mathrm{ha}^{-1}$, respectively) was calculated by averaging the corresponding quantities for the higher and lower requirements. Daily season-to-date irrigation for the center of range was calculated by averaging the daily season-to-date irrigation for the higher and lower requirements. The authors were unaware of exact, definitive guidance on optimal temporal distribution of fertilizer nitrogen. For the purpose of illustration, the fertilizer nitrogen applications for the center of range were assumed to be $70 \mathrm{~kg} \mathrm{ha}^{-1}$ at preplant, $34 \mathrm{~kg} \mathrm{ha}^{-1}$ at the 1 st fertigation opportunity, and $34 \mathrm{~kg} \mathrm{ha}^{-1}$ at the 3rd fertigation opportunity.

\section{Results and discussion}

\subsection{Input management decisions}

Across the 2017 UNL-TAPS competition, irrigation spanned a total of three months and was distributed among 21 applications. Seasonal irrigation ranged from 0 (farm 7; zero-input treatment) to $273 \mathrm{~mm}$ (farm 15), with a median of $174 \mathrm{~mm}$ (Fig. 4a). For ten farms, the half-month that received the most irrigation (or was tied for most irrigation) was the $2^{\text {nd }}$ half of July. This half-month generally coincided with low rainfall, high crop evapotranspiration (ET), and high crop sensitivity to water stress (Fig. 1). However, the irrigation amount applied during this half month was also the most variable among the contestant farms, ranging from 20 to $79 \mathrm{~mm}$. The $1^{\text {st }}$ half of August through the $1^{\text {st }}$ half of September, in contrast, accounted for less than $25 \%$ of seasonal irrigation for ten farms. The latter half of the 2017 irrigation season generally coincided with high rainfall, low crop ET, and low crop sensitivity to water stress. Overall, the majority of contestant teams appeared to have 

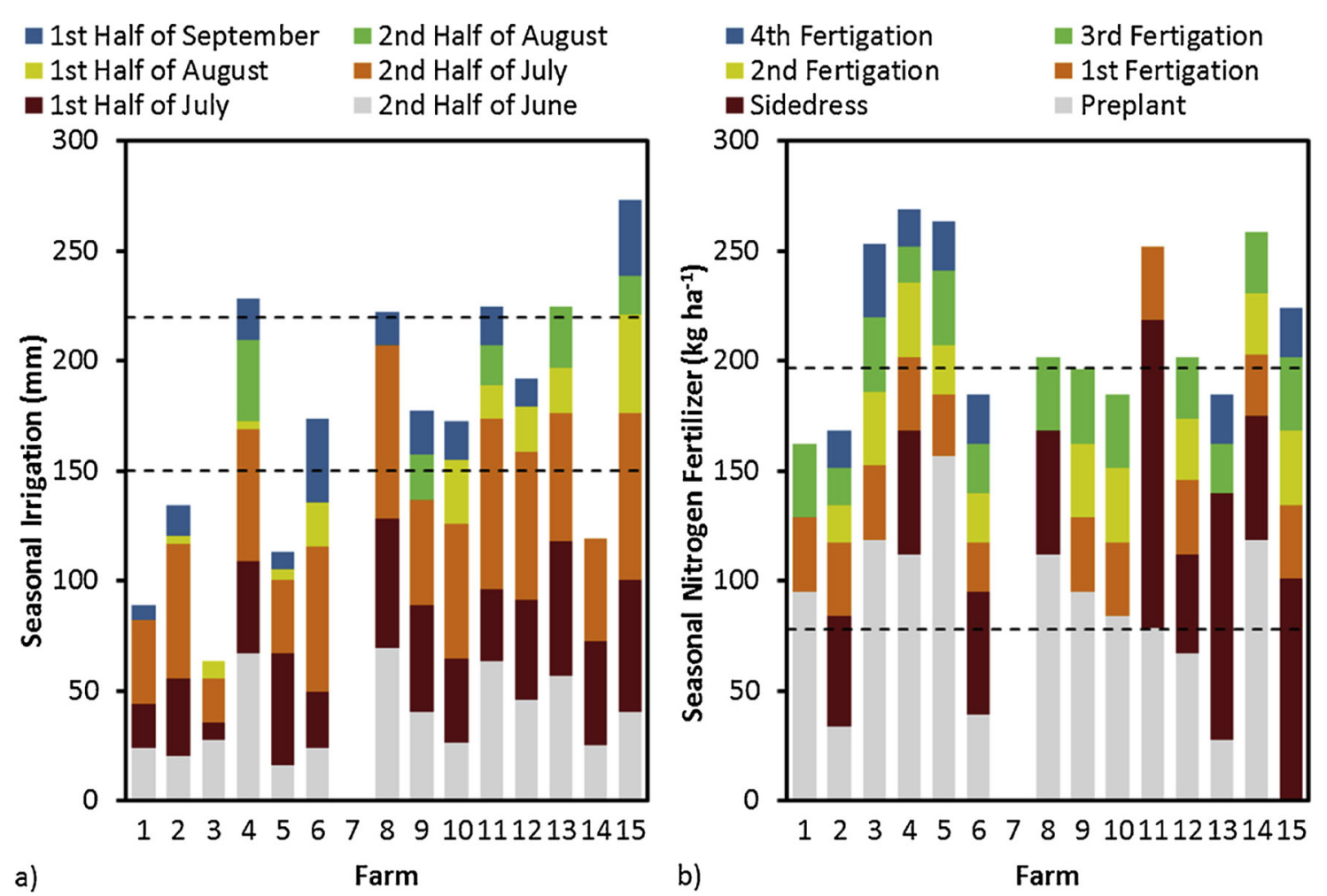

Fig. 4. Bar graph of a) seasonal irrigation and b) seasonal fertilizer nitrogen applied to each farm; the higher and lower seasonal irrigation and fertilizer nitrogen requirements are plotted as horizontal dashed lines.

accounted for such crop and weather factors to some degree in their irrigation management.

Fertilizer nitrogen was distributed among six applications over three months. Seasonal fertilizer nitrogen ranged from 0 (farm 7; zero-input treatment) to $269 \mathrm{~kg} \mathrm{ha}^{-1}$ (farm 4), with a median of $202 \mathrm{~kg} \mathrm{ha}^{-1}$ (Fig. 4b). All contestant farms except the zero-input treatment followed the university recommendation to split apply fertilizer nitrogen so that a minimum $30 \%$ of the seasonal rate is applied as sidedress and/or fertigation (Shapiro et al., 2008). The majority of farms relied on preplant and fertigation as the primary means of fertilizer nitrogen applications. At least $40 \%$ of the seasonal fertilizer nitrogen was applied as preplant for eight farms, as sidedress for three farms, and as fertigation for nine farms. Ignoring the zero-input treatment, only one farm applied no preplant, five farms applied no sidedress, and zero farms applied no fertigation. All contestant teams appeared to value the ability to apply fertilizer nitrogen during the late vegetative and early reproductive periods via fertigation. 


\subsection{Conventional efficiency indices}

Not all hybrids in the 2017 UNL-TAPS competition were described by the same production functions. Here, the Dyna-Gro D53VC55RIB hybrid not only showed above-average yield potential by achieving two of three top farm yields but also produced above-average yield given the same seasonal crop ET (Fig. 5a) or the same seasonal irrigation (Fig. 5b). This hybrid also exhibited above-average grain nitrogen content (Fig. 6a) and produced above-average yield given the same seasonal fertilizer nitrogen (Fig. 6b). Differences in production functions among hybrids in turn resulted in differences in the relationships between input quantity and efficiency indices. While one distinct curve of efficiency index versus seasonal I or seasonal F could usually be traced when examining the DynaGro D53VC55RIB hybrid alone, much more scatter was present when examining all farms together (Figs. 5c-f and 6c-f).
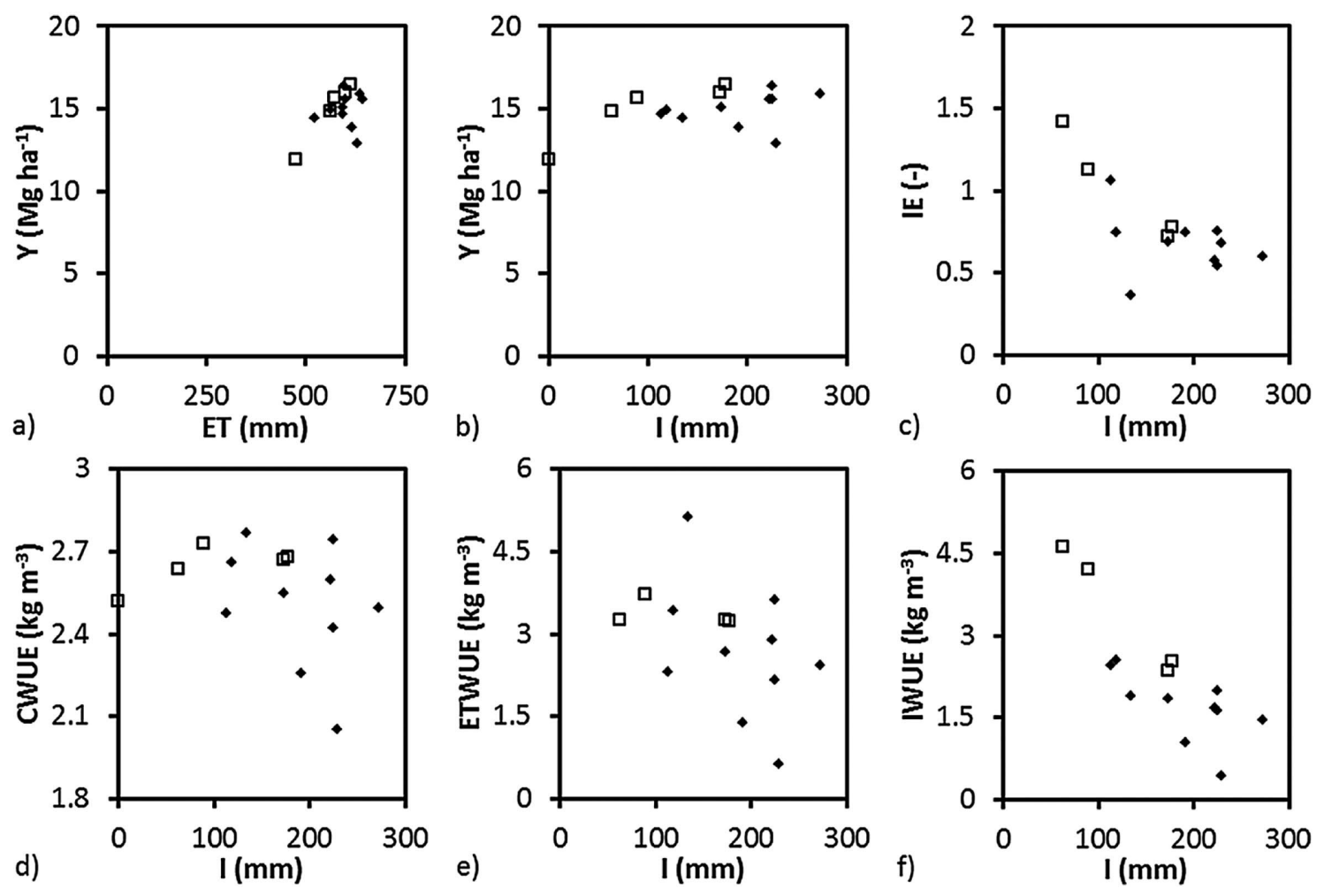

Fig. 5. Scatterplots of a) grain yield (Y) versus crop evapotranspiration (ET), b) Y versus irrigation (I), c) irrigation efficiency (IE) versus I, d) crop water use efficiency (CWUE) versus I, e) evapotranspiration water use efficiency (ETWUE) versus I, and f) irrigation water use efficiency (IWUE) versus I for the 15 contestant farms; farms with the Dyna-Gro D53VC55RIB hybrid are represented by hollow squares while other farms are represented by solid diamonds. 

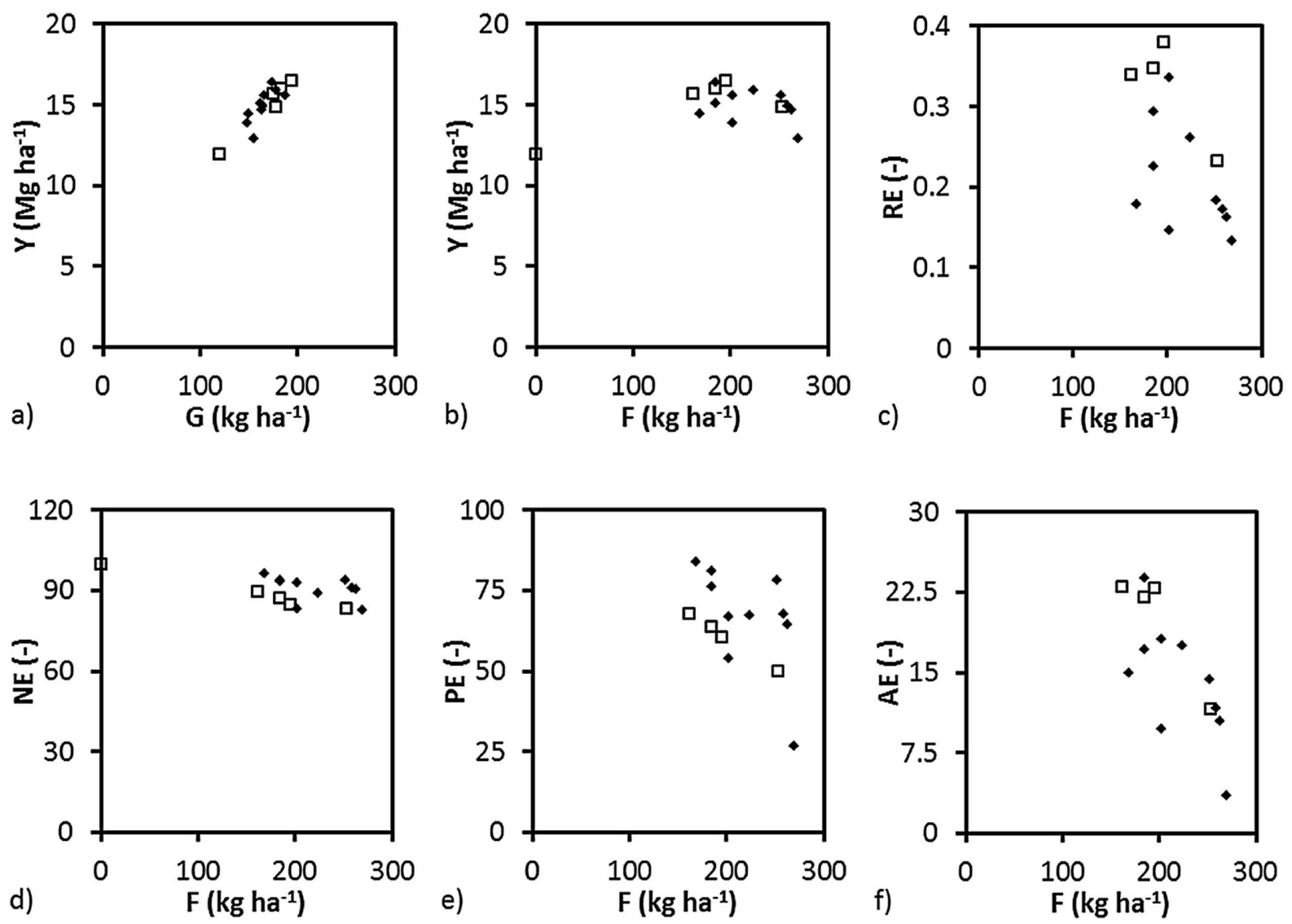

Fig. 6. Scatterplots of a) grain yield (Y) versus grain nitrogen uptake (G), b) Y versus fertilizer nitrogen $(F), \mathbf{c})$ recovery efficiency (RE) versus $F, \mathbf{d}$ ) internal efficiency (NE) versus $F, \mathbf{e}$ ) physiological efficiency (PE) versus $F$, and f) agronomic efficiency (AE) versus F; farms with the Dyna-Gro D53VC55RIB hybrid are represented by hollow squares while other farms are represented by solid diamonds.

Yield is arguably the variable that would differ most among cultivars under identical input management if all variables were measured perfectly. While water and nitrogen availability is undoubtedly important, $\mathrm{Y}$ is also affected by assimilate partitioning, stress response physiology, and many other characteristics that vary among cultivars. In contrast, different cultivars generally evapotranspire at similar rates under wellwatered conditions unless relative maturity, peak height, or peak leaf area were substantially different (Allen et al., 1996; Howell et al., 1998; Allen and Pereira, 2009; Hao et al., 2015; Nagore et al., 2017; Zhao et al., 2018). Excluding the zero-input treatment, the 2017 UNL-TAPS competition witnessed relative maturity ratings between 108 and 113 according to the seed companies, peak height between 2.4 and $3.1 \mathrm{~m}$, and peak 
leaf area above $4.5 \mathrm{~m}^{3} \mathrm{~m}^{-3}$ according to an LAI- 2200C Plant Canopy Analyzer (LI-COR Biosciences, Lincoln, NE). The optimal amount and timing of irrigation would consequently be expected to be similar among these cultivars even as yield may differ widely. The optimal seasonal rate of F, admittedly, is generally related to yield (Shapiro et al., 2008). Yet unless the study design controls for both cultivar and management and thus isolates the two types of effects, determining the optimal seasonal rate of $\mathrm{F}$ for each cultivar might be impossible, so a cultivar-blind optimal seasonal rate would need to be assumed. Therefore, a relatively uncontrolled evaluation of input management across cultivars may benefit from focusing on input amount and timing and from avoiding efficiency indices that depend on yield.

Furthermore, not all efficiency indices appear to reward appropriate seasonal input quantities. Theory described in Figs. 2a and 2c predicts that both irrigation efficiency (IE) and irrigation water use efficiency (IWUE) decrease monotonically with increasing seasonal I. The 2017 UNL-TAPS data matches this theory (Figs. 5c and 5f). The correlation coefficient between each of these two indices and seasonal I were -0.69 and -0.81 , respectively. While converting gravity irrigation to pressurized irrigation and improving the temporal distribution of I within a growing season would be constructive means of increasing the values of the two water efficiency indices, these two indices provide no meaningful information on optimal seasonal I. Likewise, theory described in Figs. 2d-f predicts that recovery efficiency (RE), internal efficiency (NE), physiological efficiency (PE), and agronomic efficiency (AE) all decrease monotonically with increasing seasonal F. The 2017 UNL-TAPS data also matches this theory (Figs. 6c-f). The correlation coefficient between each of these four indices and seasonal F were $-0.58,-0.58,-0.51$, and -0.74 , respectively. While adjusting the timing, placement, and/or product of fertilizer application to improve the spatiotemporal correspondence between nutrient availability and plant uptake would be a constructive means of increasing the values of the four nitrogen efficiency indices, these indices provide no meaningful information on optimal seasonal F. In conclusion, treatments differing only in seasonal I should not be evaluated using IE or IWUE, and treatments differing only in seasonal F should not be evaluated using RE or AE.

On the other hand, theory described in Fig. $2 \mathrm{~b}$ predicts that evapotranspiration water use efficiency (ETWUE) remains constant and then 
decreases with increasing seasonal I, whereas crop water use efficiency (CWUE) increases and then decreases with increasing seasonal I. This theoretical trend of CWUE was observed in the 2017 UNL-TAPS data (Fig. 5d) and makes CWUE suitable for evaluating seasonal I because maximum CWUE is achieved by applying the minimum seasonal I required for maximum yield. A major challenge of widely using CWUE is the difficulty of measuring crop ET accurately. Unless the climate of interest is significantly more arid than the competition site and thus allows seasonal crop ET to be estimated simply from precipitation, irrigation, and seasonal change in soil water (Howell, 2001), ET determination is generally resource intensive and prone to substantial uncertainties. Here, farm 2 achieved the highest CWUE despite applying more seasonal I than farms 1, 3, 5, and 14 and producing lower $Y$ than those four farms. This unexpected result is likely caused in part by an underestimation of ET for farm 2. By the way, if NE was calculated using aboveground nitrogen uptake (U) instead of G, NE would be completely analogous to CWUE. This version of NE would increase and then decrease with increasing seasonal $\mathrm{F}$, and the maximum index value would be achieved by applying the minimum seasonal $F$ required for maximum Y. Similarly, a major challenge of widely using this version of NE is the need to sample and analyze the aboveground biomass of enough plants for each farm under evaluation to measure $U$ accurately. Relying heavily on variables that are difficult to measure accurately is not ideal for evaluating input management.

Two outcomes of water and nitrogen interactions were observed in the 2017 UNL-TAPS competition. First, the values of the IE, ETWUE, IWUE, RE, PE, and AE indices were universally overestimated because a zero-input treatment was used as the reference. Concurrent deficiency in water and nitrogen would decrease crop ET, G, and Y by a larger magnitude than would deficiency in one input alone (Eck, 1984; Pandey et al., 2000a,b; Pandey et al., 2000a; O’Neill et al., 2004; Hernández et al., 2015). This phenomenon partly explains why IE values for farms 1,3 , and 5 exceeded $100 \%$. At the same time, the irrigation applied to these three farms would increase leaf area and root growth, enabling the plants in these farms not only to use all of the irrigation water but also to extract more stored subsoil moisture than the plants in a non-irrigated treatment are able. Second, the apparent relationship between $\mathrm{Y}$ and $\mathrm{F}$ for Dyna-Gro D53VC55RIB (Fig. 6b) misrepresented the F production 
function of this hybrid. As subsequent analyses will reveal, I and not $F$ was the dominant input driving yield differences in the 2017 UNLTAPS competition. For Dyna-Gro D53VC55RIB, increased I caused the apparent $Y$ increase with increasing medium rates of $F$, while decreased I caused the apparent $Y$ decrease with increasing high rates of $F$. In the absence of such I effects, RE and AE values of this hybrid would display a larger decrease with increasing medium rates of $\mathrm{F}$ and a smaller decrease with increasing high rates of $\mathrm{F}$ as compared with what is shown in Figs. $6 \mathrm{c}$ and $6 \mathrm{f}$. NE and PE, in contrast, are noticeably more resilient to I effects because both the numerator and denominator terms of these two indices - $\mathrm{Y}$ and G (or U)-are influenced by I. A relatively uncontrolled evaluation of input management must carefully consider all inputs plus all extraneous factors such as hail and pest damage.

\subsection{New efficiency indices}

Lamentably, the two new types of efficiency indices presented herein (equations 9-14) also depend on Y and are thus as susceptible to cultivar effects as the eight conventional efficiency indices discussed earlier. While these two new types of efficiency indices remain general indicators of overall crop performance rather than specific indicators of optimal input management, two advantages are noteworthy. First, the difficult measurements of crop ET and U need to be made on the zeroinput treatment only. This advantage greatly facilitates the use of these indices when evaluating many farms. Second, the dimensionless nature of these two new types of efficiency indices enabled the construction of water $\times$ nitrogen indices. Water $\times$ nitrogen indices are not merely more compatible with the use of a zero-input treatment that lacks both I and $\mathrm{F}$ as the reference. More importantly, water $\times$ nitrogen indices have the potential to capture the reality that, when both inputs deviate from their respective optimum quantity, the consequence is exacerbated multiplicatively. Excessive I with excessive F compounds nitrate leaching because deep percolation and nitrate concentration are simultaneously high (Gheysari et al., 2009). Deficient I with excessive F compounds soil salinization (Chen et al., 2004) and stover nitrate toxicity for livestock (Rasby et al., 2014). Excessive or deficient I with deficient F compounds nitrogen stress. Nitrate is flushed out of the root zone under excessive I (Rudnick and Irmak, 2013), whereas passive nitrogen uptake decreases with decreasing root water uptake under deficient I (Wu and Kersebaum, 

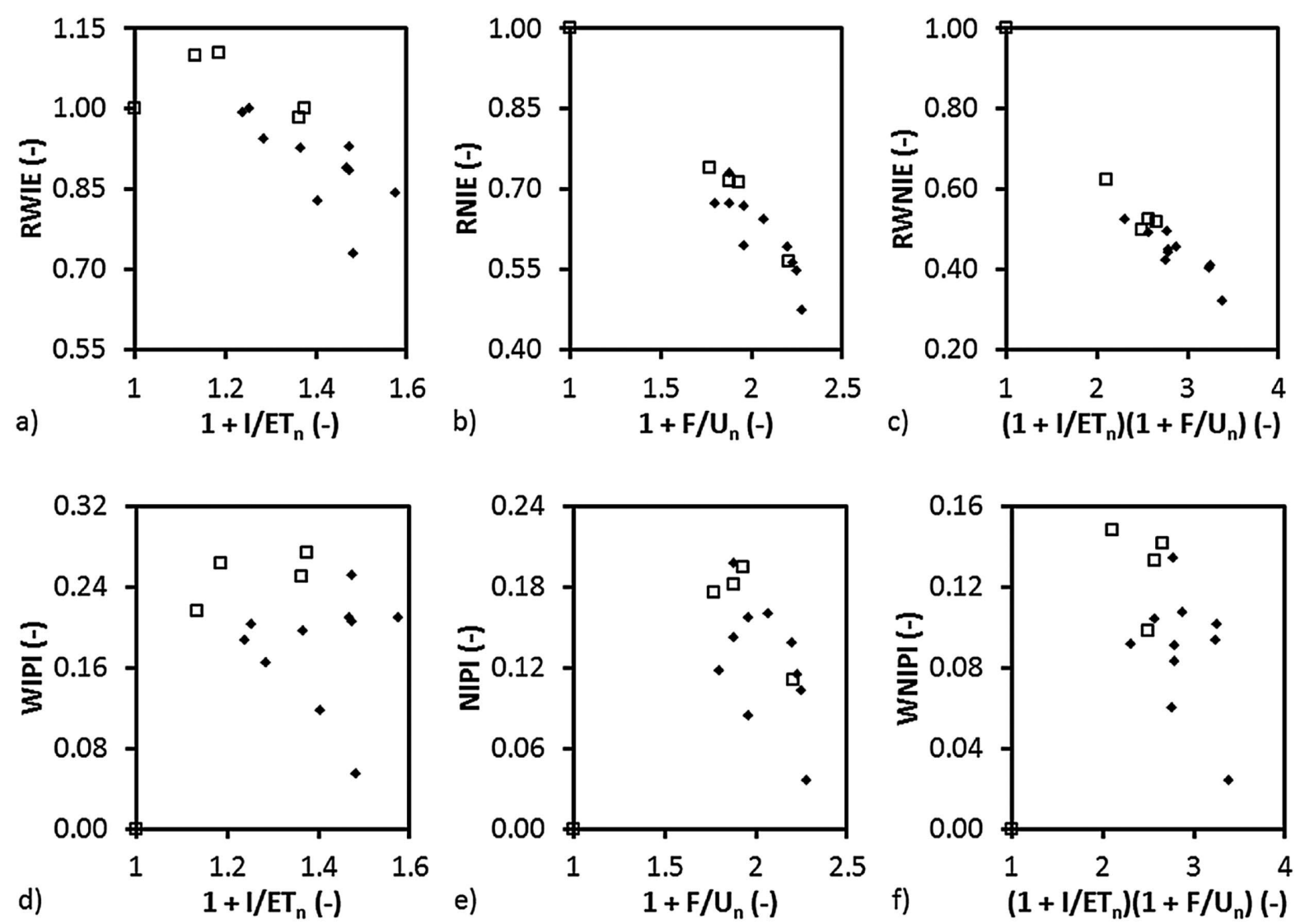

Fig. 7. Scatterplot of a) relative water input efficiency (RWIE), b) relative nitrogen input efficiency (RNIE), c) relative water×nitrogen input efficiency (RWNIE), d) water intensification performance index (WIPI), e) nitrogen intensification performance in$\operatorname{dex}(\mathrm{NIPI})$, and $\mathbf{f}$ ) water $\times$ nitrogen intensification performance index (WNIPI) versus seasonal irrigation (I) and/or fertilizer nitrogen (F) input; farms with the Dyna-Gro D53VC55RIB hybrid are represented by hollow squares while other farms are represented by solid diamonds.

2008). The authors hope that the use of water $\times$ nitrogen efficiency indices would promote more integrated thinking across the traditionally separate disciplines of irrigation management and fertilizer nitrogen management.

Just like CWUE, relative water input efficiency (RWIE) and water intensification performance index (WIPI) followed a concave-down curve-increasing and then decreasing as seasonal I increases in the 2017 UNL-TAPS competition (Fig. 7a and 7d). RWIE, however, appears to be maximized at lower seasonal I than WIPI. These two observations matches the theory described in Figs. 2g-i for the two new types of indices. The first new type of index (equations 9-11) may represent the 
priorities of a context where managed inputs are scarcer than land suitable for receiving managed inputs, so spreading the available managed input over a larger land area to produce slightly below maximum yield is preferred. The second new type of index (equations 12-14) may represent the priorities of a context where land suitable for receiving managed inputs is scarcer than managed inputs, so producing maximum yield is preferred. As discussed later, all farms excluding the zero-input treatment applied high seasonal rates of $F$ given the conditions of the 2017 UNL-TAPS competition. Consequently, these farms fell in the range where relative nitrogen input efficiency (RNIE) and nitrogen intensification performance index (NIPI) decrease monotonically with increasing seasonal $\mathrm{F}$ if cultivar effects and I effects were removed (Figs. $7 \mathrm{~b}$ and $7 \mathrm{e})$. Such high seasonal rates of $\mathrm{F}$ also caused the nitrogen term to be more influential than the water term in relative water $\times$ nitrogen input efficiency (RWNIE; Fig. 7c) and water×nitrogen intensification performance index (WNIPI; Fig. 7f). With the inclusion of lower seasonal rates of F, RWNIE and WNIPI data is expected to increase and then decrease with increasing seasonal input as predicted by theory (Fig. 2i).

\subsection{Input requirement ranges}

Unlike most efficiency indices, results from the input requirement range approach are easy to understand and interpret for diverse audiences. In the 2017 UNL-TAPS competition, six contestant farms irrigated under, four farms irrigated within, and five farms irrigated above the range spanned by the higher and lower seasonal requirements (Fig. 4a). On the other hand, one contestant farm (i.e., the zero-input treatment) fertilized under, six farms fertilized within (if counting farm 9 whose seasonal fertilizer nitrogen was equal to the higher requirement), and eight farms fertilized above the range spanned by the higher and lower seasonal requirements (Fig. 4b). Inferring from the lower requirement, six farms (including the zero-input treatment) experienced Y loss induced by water stress, whereas only the zero-input treatment experienced yield loss induced by nitrogen stress. Yield differences observed in the 2017 UNLTAPS competition that are not attributed to cultivar effects should therefore be primarily attributed to irrigation management and not fertilizer nitrogen management. Three farms were within the higher and lower seasonal requirements for both I and F. Two of these farms, furthermore, ranked in the top three for $\mathrm{Y}$ and serve as examples of producing high 
yield without excessive inputs. Meanwhile, four out of the five farms that applied excessive I also applied excessive F. The relationship between grower mentality and strategy for irrigation management and grower mentality and strategy for nitrogen management deserves further investigation and may have significant implications for extension efforts. While efficiency indices often failed to identify truly optimal seasonal input quantities, the input requirement range approach performed this task clearly and reliably. The results in turn allow I and F excesses and deficiencies to begin to be detected, analyzed, and addressed as would be expected in an effective evaluation of input management.

The input requirement range approach is conducive to evaluating not only the amount but also the timing of input applications. The same seasonal input quantity but a different application schedule may lead to significantly different outcomes. Farms 1, 4, 6, 8, 9, and 15 exemplify the diversity in the temporal distribution of irrigation during the 2017 UNL-TAPS competition (Fig. 8). For the first half of the irrigation season, farms 1 and 15 maintained cumulative irrigation slightly under the lower requirement and slightly above the higher requirement, respectively. For

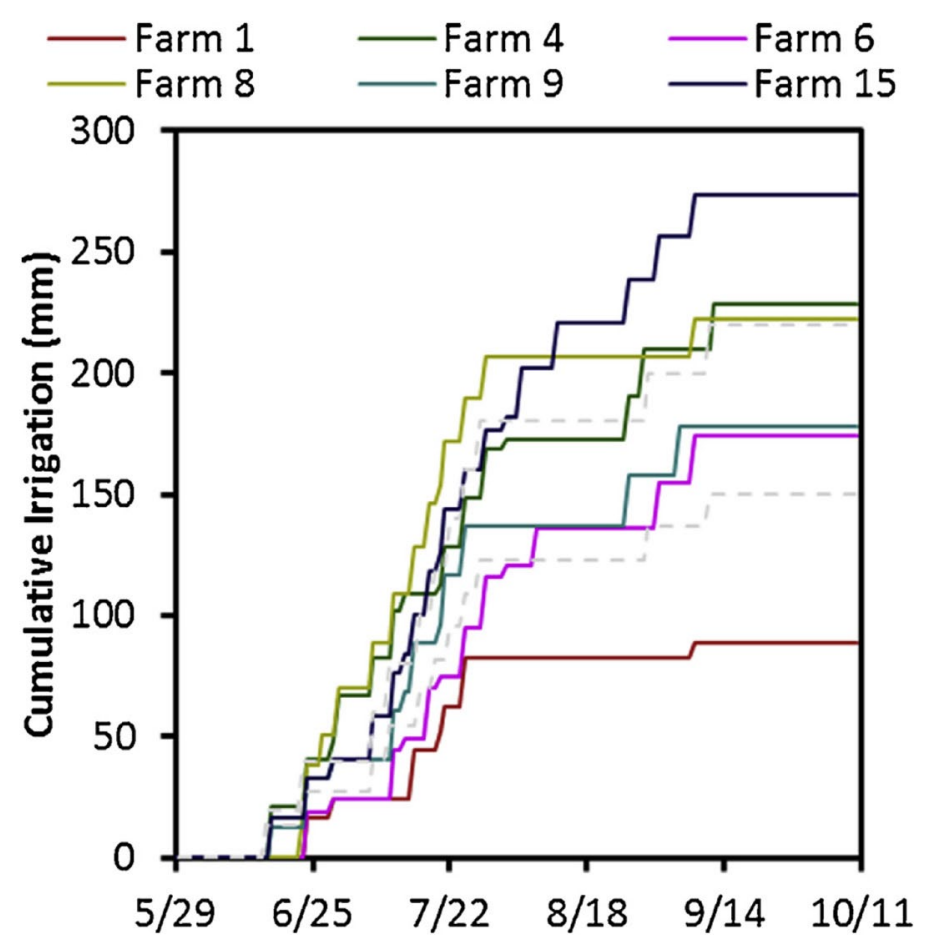

Fig. 8. Cumulative irrigation curves for farms 1, 4, 6, 8, 9, and 15 in the 2017 UNL-TAPS competition; the cumulative irrigation curves for the higher and lower irrigation requirements are plotted as grey dashed lines for comparison. 
the second half of the irrigation season, farm 1 largely withheld irrigation whereas farm 15 outpaced the higher requirement substantially. Farms 6 and 9 applied similar seasonal irrigation between the higher and lower requirements, but farm 6 postponed its irrigation and finally caught up with farm 9 in early August. Farms 4 and 8 applied similar seasonal irrigation above the higher requirement, but farm 8 applied $36 \mathrm{~mm}$ more in July than farm 4 and was not overtaken by farm 4 until late $\mathrm{Au}$ gust. Given the high sensitivity of pollination and kernel setting to water stress, farms 1, 8, and 9 were prudent to concentrate irrigation in Julythe time shortly before and during this critical period-at least as much as the higher and lower requirements did. Yet, farm 8 irrigated so generously that its cumulative irrigation remained more than $25 \mathrm{~mm}$ above the higher requirement for approximately two months almost consecutively, which may be leaving too little room in the root zone to hold heavy in-season rainfall. On the other hand, irrigating more frequently than the higher requirement during the latter half of the irrigation season as did farms 6 and 15 was not the most sensible temporal distribution of irrigation for the 2017 UNL-TAPS competition.

While the seasonal metrics (equations 15-17) merely conveyed the same information as Fig. 4, the daily metrics (equations 18-20) reflected the aforementioned differences in the timing of input application. Seasonal I and relative deviation in irrigation $\left(\mathrm{RD}_{\mathrm{I}}\right)$ of farm 8 were $6 \mathrm{~mm}$ and $15 \%$ lower, respectively, than those of farm 4 . Nevertheless, relative root mean squared deviation in irrigation ( $R R M \mathrm{RD}_{\mathrm{I}}$ ) of farm 8 was actually 38\% higher than that of farm 4 (Table 1) because farm 8 diverged much more from the irrigation schedule for the center of the requirement range than did farm 4 between July and August (Fig. 8). Seasonal $\mathrm{F}$ and relative deviation in fertilizer nitrogen $\left(\mathrm{RD}_{\mathrm{F}}\right)$ of farm 11 was $1 \mathrm{~kg} \mathrm{ha}^{-1}$ and $1 \%$ lower, respectively, than those of farm 3. Nonetheless, relative root mean squared deviation in fertilizer nitrogen $\left(\mathrm{RRMSD}_{\mathrm{F}}\right)$ of farm 11 was 26\% higher than that of farm 3 because farm 11 diverged much more from the $\mathrm{F}$ schedule for the center of the requirement range than did farm 3. Farm 11 applied $87 \%$ of its seasonal rate as preplant and sidedress, but farm 3 as well as the center of range applied roughly half of their respective seasonal rates as preplant and applied the remaining half as fertigation. As expected, absolute relative deviation in irrigation $\times$ fertilizer nitrogen $\left(\mathrm{ARD}_{\mathrm{I} \times \mathrm{F}}\right)$ was smallest for the three farms that were within the seasonal requirement range for both irrigation and 
Table 1 Unitless metrics-relative deviation in irrigation $\left(R D_{I}\right)$, relative deviation in fertilizer nitrogen $\left(\mathrm{RD}_{\mathrm{F}}\right)$, absolute relative deviation in irrigation $\times$ fertilizer nitrogen $\left(A R D_{I \times F}\right)$, relative root mean squared deviation in irrigation $\left(R R M S D_{I}\right)$, relative root mean squared deviation in fertilizer nitrogen $\left(R_{R M S D}\right)$, and relative root mean squared deviation in irrigation $\times$ fertilizer nitrogen $\left(\mathrm{RRMSD}_{\mathrm{I \times F}}\right)$ - based on the center of irrigation and fertilizer nitrogen requirement ranges for the farms of the 2017 UNLTAPS competition.

\begin{tabular}{lrrrrrr} 
Farm & $\mathrm{RD}_{\mathrm{I}}$ & $\mathrm{RD}_{\mathrm{F}}$ & $\mathrm{ARD}_{\mathrm{I} \times \mathrm{F}}$ & $\mathrm{RRMSD}_{\mathrm{I}}$ & $\mathrm{RRMSD}_{\mathrm{F}}$ & RRMSD $_{\mathrm{I} \times \mathrm{F}}$ \\
\hline 1 & -0.52 & 0.18 & 0.80 & 0.32 & 0.18 & 0.57 \\
2 & -0.27 & 0.22 & 0.56 & 0.17 & 0.21 & 0.41 \\
3 & -0.66 & 0.84 & 2.06 & 0.41 & 0.65 & 1.32 \\
4 & 0.24 & 0.96 & 1.42 & 0.15 & 0.80 & 1.07 \\
5 & -0.39 & 0.92 & 1.66 & 0.24 & 0.78 & 1.20 \\
6 & -0.06 & 0.35 & 0.43 & 0.10 & 0.27 & 0.40 \\
7 & -1.00 & -1.00 & 3.00 & 0.66 & 0.83 & 2.04 \\
8 & 0.20 & 0.47 & 0.76 & 0.21 & 0.47 & 0.78 \\
9 & -0.04 & 0.43 & 0.48 & 0.05 & 0.35 & 0.41 \\
10 & -0.07 & 0.35 & 0.44 & 0.07 & 0.27 & 0.36 \\
11 & 0.21 & 0.84 & 1.23 & 0.16 & 0.81 & 1.10 \\
12 & 0.04 & 0.47 & 0.52 & 0.08 & 0.38 & 0.49 \\
13 & 0.21 & 0.35 & 0.64 & 0.18 & 0.34 & 0.58 \\
14 & -0.35 & 0.88 & 1.55 & 0.19 & 0.77 & 1.12 \\
15 & 0.48 & 0.63 & 1.41 & 0.29 & 0.52 & 0.97 \\
\hline
\end{tabular}

fertilizer nitrogen. It was largest for farm 3, which applied the second lowest seasonal irrigation but the fourth highest seasonal fertilizer nitrogen among all contestant farms, and for farm 7, the zero-input treatment. Because farm 8 had a high RRMSD given its $\mathrm{RD}_{1}$ and because farm 11 had a high $\mathrm{RRMSD}_{\mathrm{F}}$ given its $\mathrm{RD}_{\mathrm{F}}$, farms 8 and 11 each had a relatively high relative root mean squared deviation in irrigation $\times$ fertilizer nitrogen (RRMSD ${ }_{\mathrm{I} \times \mathrm{F}}$ ) given their respective $\mathrm{ARD}_{\mathrm{I} \times \mathrm{F}}$.

Plant tissue analyses support the diagnosis by the requirement range approach that high seasonal rates of $\mathrm{F}$ were pervasive in the 2017 UNLTAPS competition. Excluding the three plots of the zero-input treatment, all but two plots reported stalk nitrate levels in the high category of $>2000 \mathrm{ppm} \mathrm{NO}_{3}$-N (Fig. 9b; Sawyer and Mallarino, 2018). The observation that the higher requirement for seasonal $\mathrm{F}$ was $119 \mathrm{~kg} \mathrm{ha}^{-1}(153 \%)$ above the lower requirement and also resulted in high stalk nitrate levels highlights the uncertainty in current predictions of $\mathrm{F}$ requirements. 

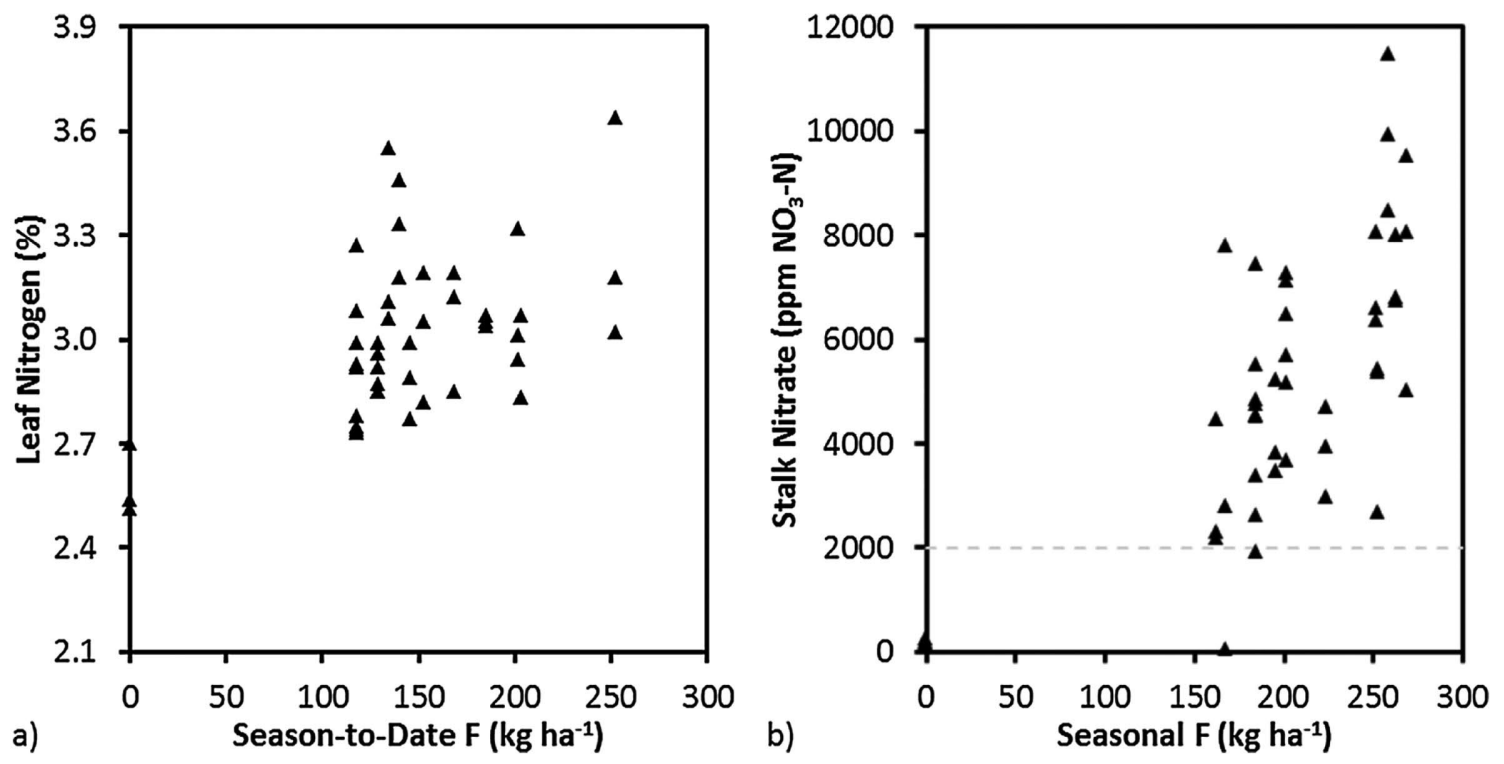

Fig. 9. Scatterplots of a) nitrogen content of the uppermost collared leaf at the V14 growth stage versus season-to-date fertilizer nitrogen $(\mathrm{F})$ and $\mathbf{b})$ stalk nitrate content after physiological maturity versus seasonal $\mathrm{F}$ for each of the 45 plots in the 2017 UNLTAPS competition; stalk nitrate above $2000 \mathrm{ppm} \mathrm{NO}_{3}-\mathrm{N}$ (grey dashed line) is classified as high according to Sawyer and Mallarino (2018).

The large discrepancy between the higher and lower requirements may be attributed in part to above-average pre-season temperatures in 2017. Between 7 March (i.e., day after soil nitrate sampling in 2017) and 8 May (i.e., day before planting in 2017), the daily averages of maximum and minimum temperature were $1.4^{\circ} \mathrm{C}$ higher on average for 2017 than for the 1987-2016 mean (HPRCC, 2018). The higher requirement was based on soil testing and assumptions of average weather conditions, so it cannot account for any temperature-driven increase in nitrogen mineralization after the soil sampling date. Given the inability of traditional F recommendation algorithms to adapt to deviations from normality, emerging technologies such as in-season nitrogen simulation models, nitrate-specific soil sensors, and active optical sensors would be needed to overcome this problem. Leaf nitrogen tests may be informative as well. By the V14 growth stage, all contestant farms except the zero-input treatment had applied more $\mathrm{F}$ than the lower requirement. The nitrogen content of the uppermost collared leaf was above $2.7 \%$ for every plot of these farms but not for any plot of the zero-input treatment (Fig. 9a). All methods are associated with some degree of uncertainty and 
may each experience difficulty distinguishing between deficient, sufficient, and excessive nitrogen availability under different circumstances. Thus, using an ensemble of multiple methods may be the best means of in-season F management (Thompson et al., 2015).

There are particular challenges of using emerging technologies for nitrogen management in the presence of multiple stresses. For instance, active optical sensors may unintentionally respond to both water stress and nitrogen stress. Normalized difference red edge (NDRE) is a vegetation index that is commonly calculated from red edge and near infrared active reflectance as an indicator of crop nitrogen status (Shiratsuchi et al., 2011). Canopy temperature is commonly calculated from infrared thermometer data as an indicator of crop water status (Idso et al., 1981; Jackson et al., 1981). Yet on two dates around the VT/R1 growth stage and on two dates during plant senescence, the correlation between NDRE and canopy temperature was $-0.71,-0.80,-0.78$, and -0.77 , respectively, for the plots of the 2017 UNL-TAPS competition (Figs. 10a-d). The key to unfolding this mystery lies in the fact that water stress generally decreases leaf area. Water stress during the vegetative period reduces leaf expansion. Indeed, correlation between vegetative period irrigation and peak leaf area index was 0.72 for the 2017 UNL-TAPS competition. Water stress during the reproductive period, on the other hand, accelerates leaf senescence (Rudnick and Irmak, 2014). Because the active optical sensors were placed between crop rows and were oriented nadir, the NDRE measurements were sensitive to leaf area even when the canopy would be considered to be effectively closed. Therefore, on the four warm and clear days featured in Fig. 10, the underirrigated plots showed both low NDRE and high canopy temperatures regardless of crop nitrogen status. NDRE values that have been dragged down by water stress should be used with caution to avoid underestimating crop nitrogen status and overestimating in-season F needs. Research on this subject is ongoing (Shiratsuchi et al., 2011; Ward, 2015).

\subsection{Applicability}

The input requirement range approach may be the generally most preferred method to evaluate grower I and $\mathrm{F}$ amount and timing. From a grower's perspective, it is actually better to have a requirement range to stay within rather than a magical (i.e., optimal) number to aim for. 

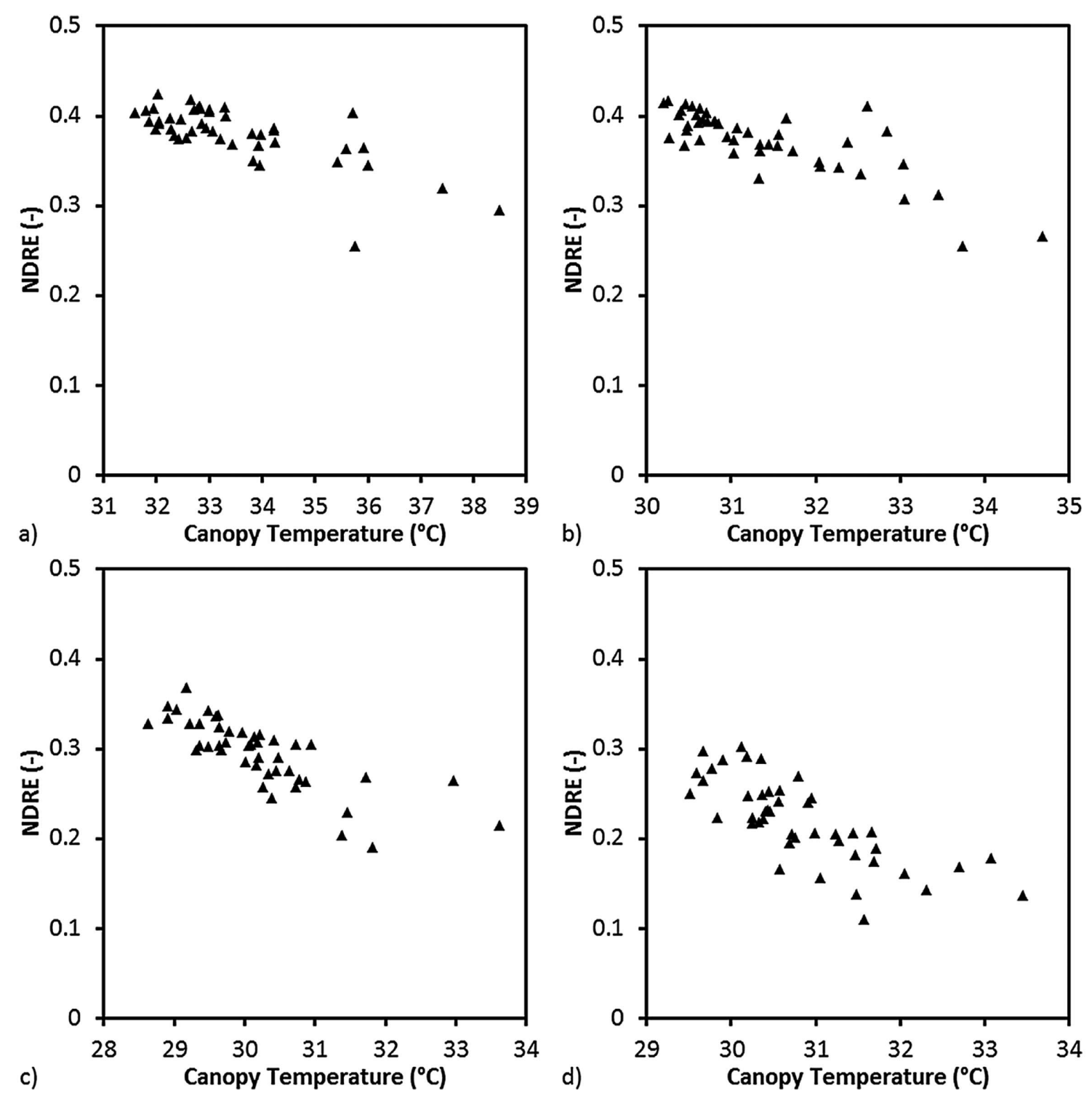

Fig. 10. Scatterplots of normalized difference red edge (NDRE) vegetation index versus canopy temperature on a) 19 July, b) 24 July, c) 11 September, and d) 21 September 2017 for each of the 45 plots in the 2017 UNL-TAPS competition.

Drivers informed by a fuel gauge can decide the amount and timing of their fuel purchases by further considering their driving plan, their proximity to filling stations, and spatiotemporal predictions of fuel price. Likewise, growers informed by an input requirement range can decide the amount and timing of their input application by further considering their labor availability, their equipment capabilities, and past and future 
weather. Also, the ability to analyze temporal distributions is a particularly noteworthy strength. Producing a graph such as Fig. 8 for both I and F would summarize the evaluation effectively. Diagnosing when and how much growers are over- or under-applying inputs would then initiate conversation about current technological and non-technological challenges and how to improve in future seasons.

The higher requirement for I and F should be easier to establish than the lower requirement. The higher requirement for I can be calculated from growth stage $\mathrm{K}_{\mathrm{c}}$, local weather data, start-of-season soil moisture, and university recommendations on soil water depletion. The higher requirement for $\mathrm{F}$ can be obtained from widely tested university algorithms based on basic information such as soil test results, previous crop, and Y goal. As for the lower requirement for I and F, a gradient of I levels and a gradient of $F$ levels could be imposed at a centralized location. In some environments, care would need to be taken to account for the effect of soil moisture and soil nitrogen levels carrying over from one season to the next. Also, if the declining segment of the production functions is present and the plateau segment is short, a factorial design would be necessary instead of separate gradients for I and F. Multiple cultivars could be included if cultivar differences are suspected to influence the lower requirement. The higher and lower requirements might be directly applicable across a small non-mountainous area (perhaps $\lesssim 1000 \mathrm{~km}^{2}$ ) with similar soil and similar past management. Yet if the fields under evaluation are spread over a larger area or are more heterogeneous, the lower requirement may need to be determined experimentally at multiple locations or extrapolated from one location to other locations using crop models. With increasing prevalence of variable rate application technology and improving accuracy of crop models, establishing the lower requirement would continue to become easier.

Aspects of the input requirement range approach would benefit from further investigation. Better understanding of the spatial variability of higher and lower requirements would facilitate the evaluation of multiple fields. Also, although this paper focused on post-season evaluations, the potential of predicting higher and lower requirements in real-time to inform in-season decision-making deserves greater exploration. Additionally, the most suitable assumptions for each context would need to be discovered. For instance, this paper evaluated the temporal distribution of I and F in terms of daily season-to-date cumulative input 
amounts, which relied on the assumption that in-season losses were uniformly negligible. In regions or seasons where this assumption is false, the evaluation may need to be conducted in terms of soil moisture content and soil inorganic nitrogen content instead. Finally, how to best use the results of the input requirement approach in a follow-up conversation with growers would need to be learned. Colleagues are highly encouraged to try, assess, and adapt the input requirement range approach and then share their experiences through journal publication and/or direct correspondence with the authors.

\section{Conclusion}

Efficiency indices have been successfully used to compare agricultural regions, parameterize crop models, and contrast irrigation systems and fertilizer programs. Yet among conventional efficiency indices, only crop water use efficiency and physiological efficiency (if calculated from aboveground nitrogen uptake rather than grain nitrogen uptake) are maximized at an apparently optimal input level instead of never increasing with input level. Alternate efficiency indices presented in this paper capture similar information as crop water use efficiency and physiological efficiency while minimizing the need to make difficult measurements of crop evapotranspiration and aboveground nitrogen uptake. Nonetheless, the alternate indices also depend on yield, whose sensitivity to cultivar differences can obscure evaluation of input management. Overall, efficiency indices were found to be less than ideal for evaluation of grower irrigation and fertilizer nitrogen amount and timing.

In contrast, the input requirement range approach proposed in this paper clearly points out when and by how much growers are over- or under-applying inputs. This approach was not only capable of assessing seasonal input quantities but also distinguishing more appropriate and less appropriate temporal distributions that totaled to the same seasonal quantity. The input requirement range approach meets the three criteria set forth in the introduction. First, input management ranges can consider both irrigation and nitrogen management when aiming for (near) maximum yield. Second, input management ranges are flexible to any temporal distribution of irrigation and fertilizer because it can analyze on a daily, weekly, monthly, or seasonal time step. Third, 
input management ranges are relatively resistant to cultivar effects because the evaluation does not directly depend on yield. Therefore, the input requirement range approach is especially recommended for less controlled evaluations in on-station competitions and on-farm research where more structured statistical analyses might be impossible.

Acknowledgments The authors are grateful to Turner Dorr, Jacob Nickel, Jasreman Singh, Brian Krienke, Raïssa Urujeni, Odile Umuhoza, and Devin Broadhead for their involvement with data collection; Julie Peterson, Tony Adesemoye, Gary Mahnken, and Merle Still for their supporting roles in field management; and Lindsay Corporation, Holzfasters Irrigation, Agri-Inject, SureFire Ag Systems, LI-COR Biosciences, and Ward Laboratories for their timely technical support. The authors also thank all partners and sponsors of the UNL-TAPS program. This paper is based upon work that was jointly supported by the United States Department of Agriculture's National Institute of Food and Agriculture under award number 2016-68007-25066, "Sustaining agriculture through adaptive management to preserve the Ogallala aquifer under a changing climate", and under Hatch project 1015698; the Nebraska Corn Board under award number 88-R-1819-10; the Daugherty Water for Food Global Institute; and University of Nebraska-Lincoln Institute of Agriculture and Natural Resources.

\section{References}

Allen, R.G., Pereira, L.S., 2009. Estimating crop coefficients from fraction of ground cover and height. Irrig. Sci. 28 (1), 17-34. https://doi.org/10.1007/ s00271-009-0182-z

Allen, R.G., Pereira, L.S., Raes, D., Smith, M., 1996. Crop Evapotranspiration: Guidelines for Computing Crop Water Requirements. FAO Irrigation and Drainage Paper 56. Food and Agriculture Organization, Rome, Italy.

Allen, R.G., Walter, I.A., Elliot, R.L., Howell, T.A., Itenfisu, D., Jensen, M.E., Snyder, R.L., 2005. ASCE Standardized Reference Evapotranspiration Equation. Environmental and Water Resources Institute of the American Society of Civil Engineers, Reston, VA.

Bartlett, A.C., Andales, A.A., Arabi, M., Bauder, T.A., 2015. A smartphone app to extend use of a cloud-based irrigation scheduling tool. Comput. Electron. Agric. 111, 127-130. https://doi.org/10.1016/j.compag.2014.12.021

Chen, Q., Zhang, X., Zhang, H., Christie, P., Li, X., Horlacher, D., Liebig, H.-P., 2004. Evaluation of current fertilizer practice and soil fertility in vegetable production in the Beijing Region. Nutr. Cycl. Agroecosyst. 69 (1), 51-58. https://doi. org/10.1023/B:FRES.0000025293.99199.ff 
Dobermann, A., 2007. Nutrient use efficiency-measurement and management. In: Krauss, A., Isherwood, K., Heffer, P. (Eds.), Fertilizer Best Management Practices: General Principles, Strategy for Their Adoption and Voluntary Initiatives Versus Regulations. International Fertilizer Industry Association, Paris, France, pp. 1-28. Online @ https://www.fertilizer.org//images/Library Downloads/2007 IFA FBMP\%20Workshop Brussels.pdf

Eck, H.V., 1984. Irrigated corn yield response to nitrogen and water. Agron. J. 76 (3), 421-428. https://doi.org/10.2134/agronj1984.00021962007600030014x

Ferguson, R.B., 2015. Groundwater quality and nitrogen use efficiency in Nebraska's Central Platte River Valley. J. Environ. Qual. 44 (2), 449-459. https://doi. org/10.2134/jeq2014.02.0085

Gheysari, M., Mirlatifi, S.M., Homaee, M., Asadi, M.E., Hoogenboom, G., 2009. Nitrate leaching in a silage maize field under different irrigation and nitrogen fertilizer rates. Agric. Water Manag. 96 (6), 946-954. https://doi.org/10.1016/j. agwat.2009.01.005

Hao, B., Xue, Q., Marek, T.H., Jessup, K.E., Hou, X., Xu, W., Bynum, E.D., Bean, B.W., 2015. Soil water extraction, water use, and grain yield by drought-tolerant maize on the Texas High Plains. Agric. Water Manag. 155, 11-21. https://doi. org/10.1016/j.agwat.2015.03.007

Hernández, M., Echarte, L., Maggiora, A.D., Cambareri, M., Barbieri, P., Cerrudo, D., 2015. Maize water use efficiency and evapotranspiration response to $\mathrm{N}$ supply under contrasting soil water availability. Field Crops Res. 178, 8-15. https://doi. org/10.1016/i.fcr.2015.03.017

Howell, T.A., 2001. Enhancing water use efficiency in irrigated agriculture. Agron. J. 93 (2), 281-289. https://doi.org/10.2134/agronj2001.932281x

Howell, T.A., Tolk, J.A., Schneider, A.D., Evett, S.R., 1998. Evapotranspiration, yield, and water use efficiency of corn hybrids differing in maturity. Agron. J. 90 (1), 3-9 https://doi.org/0.2134/agronj1998.00021962009000010002x

HPRCC, 2018. Automated Weather Data Network: Classic Online Services. Online @ High Plains Regional Climate Center. http://awdn.unl.edu/classic/home.cgi

Idso, S.B., Jackson, R.D., Pinter Jr., P.J., Reginato, R.J., Hatfield, J.L., 1981. Normalizing the stress-degree-day parameter for environmental variability. Agric. Meteorol. 24, 45-55. https://doi.org/10.1016/0002-1571(81)90032-7

Jackson, R.D., Idso, S.B., Reginato, R.J., Pinter Jr., P.J., 1981. Canopy temperature as a crop water stress indicator. Water Resour. Res. 17 (4), 1133-1138. https://doi. org/10.1029/WR017i004p01133

Nagore, M.L., Maggiora, A.D., Andrade, F.H., Echarte, L., 2017. Water use efficiency for grain yield in an old and two more recent maize hybrids. Field Crops Res. 214, 185-193. https://doi.org/10.1016/j.fcr.2017.09.013

NRCS, 2004. Chapter 9: Hydrologic soil cover complexes. In: National Engineering Handbook Part 630: Hydrology. United States Department of Agriculture Washington, DC. Online @ https://www.wcc.nrcs.usda.gov/ftpref/wntsc/H\&H/ NEHhydrology/ch9.pdf 
O’Neill, P.M., Shanahan, J.F., Schepers, J.S., Caldwell, R.M., 2004. Agronomic responses of corn hybrids from different eras to deficit and adequate levels of water and nitrogen. Agron. J. 96 (6), 1660-1667. https://doi.org/10.2134/agronj2004.1660

Pandey, R.K., Maranville, J.W., Admou, A., 2000a. Deficit irrigation and nitrogen effects on maize in a sahelian environment: I. Grain yield and yield components. Agric. Water Manag. 46 (1), 1-13. https://doi.org/10.1016/ $\underline{\mathrm{S} 0378-3774(00) 00073-1}$

Pandey, R.K., Maranville, J.W., Chetima, M.M., 2000b. Deficit irrigation and nitrogen effects on maize in a sahelian environment: II. Shoot growth, nitrogen uptake, and water extraction. Agric. Water Manag. 46 (1), 15-27. https://doi.org/10.1016/ $\underline{\mathrm{S} 0378-3774(00) 00074-3}$

Rasby, R.J., Anderson, B.E., Kononoff, P.J., 2014. Nitrates in Livestock Feeding. NebGuide G1779. Online @ University of Nebraska-Extension, Lincoln, NE. http://extensionpublications.unl.edu/assets/pdf/g1779.pdf

Rudnick, D.R., Irmak, S., 2013. Impact of water and nitrogen management strategies on maize yield and water productivity indices under linear-move sprinkler irrigation. Trans. ASABE 56 (5), 1769-1783. https://doi.org/10.13031/ $\underline{\text { trans.56.10215 }}$

Rudnick, D.R., Irmak, S., 2014. Spatial and temporal maize soil water extraction (Depletion) dynamics: part II. Impact of water and nitrogen management strategies on soil water extraction. Trans. ASABE 57 (2), 445-462. https://doi. org/10.13031/trans.57.10254

Rudnick, D.R., Djaman, K., Irmak, S., 2015. Performance analysis of capacitance and electrical resistance-type soil moisture sensors in a silt loam soil. Trans. ASABE 58 (3), 649-665. https://doi.org/10.13031/trans.58.10761

Rudnick, D.R., Irmak, S., West, C., Chávez, J.L., Kisekka, I., Marek, T.H., Schneekloth, J.P., Mitchell McCallister, D., Sharma, V., Djaman, K., Aguilar, J., Schipanski, M.E., Rogers, D.H., Schlegel, A., 2018. Deficit irrigation management of maize in the High Plains Aquifer Region: a review. J. Am. Water Resour. Assoc (in-press).

Sawyer, J.E., Mallarino, A.P., 2018. Use of the End-of-Season Corn Stalk Nitrate Test in Iowa Corn Production. CROP 3154. Retrieved from. Iowa State University Extension and Outreach, Ames, Iowa. https://store.extension.iastate.edu/ product $/ 5089$

Shapiro, C.A., Ferguson, R.B., Hergert, G.W., Wortmann, C.S., Walters, D.T., 2008. Fertilizer Suggestions for Corn. Extension Circular EC117. Retrieved from. University of Nebraska-Lincoln Extension, Lincoln, NE. http:// extensionpublications.unl.edu/assets/pdf/ec117.pdf

Shaver, T.M., Kruger, G.R., Rudnick, D.R., 2017. Crop canopy sensor orientation for late season nitrogen determination in corn. J. Plant Nutr 40 (15), 2217-2223. https://doi.org/10.1080/01904167.2017.1346681

Shiratsuchi, L.S., Ferguson, R.B., Shanahan, J.F., Adamchuk, V.I., Rundquist, D.C., Marx, D.B., Slater, G.P., 2011. Water and nitrogen effects on active canopy sensor vegetation indices. Agron. J. 103 (6), 1815-1826. https://doi.org/10.2134/ agronj2011.0199 
Singh, J., Lo, T., Rudnick, D.R., Dorr, T.J., Burr, C.A., Werle, R., Shaver, T.M., MuñozArriola, F., 2018. Performance assessment of factory and field calibrations for electromagnetic sensors in a loam soil. Agric. Water Manag. 196, 87-98. https:// doi.org/10.1016/i.agwat.2017.10.020

Taghvaeian, S., Chávez, J.L., Hansen, N.C., 2012. Infrared thermometry to estimate crop water stress index and water use of irrigated maize in Northeastern Colorado. Remote Sens. (Basel) 4, 3619-3637. https://doi.org/10.3390/ $\underline{\text { rs4113619 }}$

Thompson, L.J., Ferguson, R.B., Kitchen, N.R., Frazen, D.W., Mamo, M., Yang, H., Schepers, J.S., 2015. Model and sensor-based recommendation approaches for inseason nitrogen management in corn. Agron. J. 107 (6), 2020-2030. https://doi. org/10.2134/agronj15.0116

Ward, N.C., 2015. Nitrogen and Water Effects on Canopy Sensor Measurements for Site- Specific Management of Crops (Doctoral dissertation). University of Nebraska-Lincoln, Lincoln, NE Retrieved from https://digitalcommons.unl.edu/ agronhortdiss/91/

Wortmann, C.S., Klein, R.N., Shapiro, C.A., 2012. Harvesting Crop Residues. NebGuide G1846. Retrieved from. University of Nebraska-Lincoln Extension, Lincoln, NE. http://extensionpublications.unl.edu/assets/pdf/g1846.pdf

Wu, L., Kersebaum, K.C., 2008. Modeling Water and nitrogen interaction responses and their consequences in crop models. In: Ahuja, L.R., Reddy, V.R., Saseendran, S.A., Yu, Q. (Eds.), Advances in Agricultural Systems Modeling 1. Response of Crops to Limited Water: Understanding and Modeling Water Stress Effects on Plant Growth Processes. ASA, CSSA, \& SSSA, Madison, WI, pp. 215-249. https:// doi.org/10.2134/advagricsystmodel1.c8

Zhao, J., Xue, Q., Jessup, K.E., Hao, B., Hou, X., Marek, T.H., Xu, W., Evett, S.R., O'Shaughnessy, S.A., Brauer, D.K., 2018. Yield and water use of drought-tolerant maize hybrids in a semiarid environment. Field Crops Res. 216, 1-9. https://doi. org/10.1016/i.fcr.2017.11.001 